Running head: IDENTITY FUSION META-ANALYSIS

THIS IS A PREPRINT OF A MANUSCRIPT ACCEPTED FOR PUBLICATION AT EUROPEAN REVIEW OF SOCIAL PSYCHOLOGY.

How Identity Fusion Predicts Extreme Pro-Group Orientations: A Meta-Analysis

Anders Hustad Varmann ${ }^{1}$, Line Kruse ${ }^{2+}$, Kinga Bierwiaczonek ${ }^{1+}$, Ángel Gómez ${ }^{3,4}$, Alexandra Vázquez ${ }^{3,4}$, and Jonas R. Kunst ${ }^{1 *}$

1. Department of Psychology, University of Oslo, Norway

2. Department of Linguistics, Cognition and Semiotics, University of Aarhus, Denmark

3. ARTIS International, St. Michaels, Maryland, U.S.A.

4. Department of Social and Organizational Psychology, Faculty of Psychology, Universidad Nacional de Educación a Distancia, UNED, Madrid, Spain

*Corresponding author + Shared second authors

Correspondence concerning this article should be addressed to Jonas R. Kunst, j.r.kunst@psykologi.uio.no, Postboks 1094, Blindern, 0317 Oslo, Norway 


\begin{abstract}
Researchers have productively tested identity fusion theory, aiming to explain extreme progroup orientations. However, the strength of effects, types of measurements, and study contexts have varied substantially. This first meta-analysis (90 studies from 55 reports, 106 effects, $N=36,880$ ) supported four main conclusions based on the available literature: (1) identity fusion has a strong and positive but very heterogeneous relationship with extreme pro-group orientations; (2) its effect is significantly stronger than that of social identification; however, some evidence suggests that this difference is primarily observed in published rather than unpublished studies; (3) the verbal identity fusion scale has the best explanatory power; (4) identity fusion is most strongly associated with extreme collective action, followed by a willingness to sacrifice oneself, fight or die for the group, and outgroup hostility. We discuss the findings' implication for identity fusion theory. Based on the literature's limitations, we highlight avenues for future research.
\end{abstract}

Key words: extremism, identity fusion, social identity, violence, meta-analysis 


\section{How Identity Fusion Predicts Extreme Pro-Group Orientations: A Meta-Analysis}

Twenty years ago, Al-Qaida operatives hijacked four airplanes carrying hundreds of passengers and crewmembers. Two planes hit the World Trade Centre in New York City, one targeted the Pentagon building, and one crashed in a field outside Pennsylvania. The attacks of 9/11 are clearly among the worst and most consequential terrorist attacks in recorded history. Even when considering that the consequences reverberate to this day, the attacks are not unique in the sense that, as for most terrorist attacks, the perpetrators acted not on behalf of themselves or purely egotistic motives but instead on behalf of a group or cause. The dedication and terminal sacrifices committed by the terrorists indicate a personal alignment to group goals that promotes extreme behaviour, greatly outweighing personal safety and wellbeing concerns.

To explain the mechanisms driving violent extremism and extreme pro-group orientations, we originated or extended identity fusion theory (Gómez et al., 2011a, 2011b, 2020; Swann et al., 2009, 2012). The theory assumes that extreme pro-group actions are driven by a visceral feeling of "oneness" with the group. Indeed, across a broad range of often interdisciplinary studies in different cultures and contexts, identity fusion has demonstrated seemingly great explanatory and predictive power in terms of extreme progroup outcomes (for recent reviews, see Atran, 2021; Gómez et al., 2020; Whitehouse, 2018). Moreover, in a recent systematic review, identity fusion was found to be the strongest predictor of radical intentions among tens of alternative variables (Wolfowicz et al., 2021).

However, despite researchers having published productively on the role of identity fusion for more than a decade, a meta-analysis of the field is missing. Considering the varied applications of identity fusion to different contexts and settings and its varying strength of 
effects, we present a meta-analysis that estimates the effect of identity fusion on extreme progroup orientations across the available published and unpublished research.

Importantly, as the heterogeneity ${ }^{1}$ of effects can be expected to be high in a field with diverse methods and contexts, we aim to answer questions central to the theory by testing various moderating factors. Specifically, we investigate whether identity fusion predicts extreme pro-group outcomes beyond social identification, which is commonly measured alongside identity fusion in studies. Further, we test whether the effect of identity fusion depends on which country people live in and sample demographics, the target group of the identity fusion that is assessed (e.g., one's country/nation, kinship group, etc.), the choice of identity fusion scale, and how extreme pro-group outcomes are assessed.

\section{The Theory of Identity Fusion}

The theory of identity fusion was originally conceived to explain the intragroup mechanisms and alignments with groups that foster extreme pro-group behaviours or intentions (Swann et al., 2009, 2012). Initially, the theory was developed to help explain the 9/11 attacks and 2004 Madrid train bombings (Europe's worst terrorist attack to that date). Its properties and nature were empirically validated in several publications (e.g., Gómez et al., 2011a, 2011b; Swann et al., 2009, 2010) and formally established as a theory (Swann et al., 2012). The theory's core construct, identity fusion, was further shown to explain extreme behavioural intentions cross-culturally in five continents (Swann et al., 2014a).

However, as could be expected in a field dominated by social identity theory for a long time, identity fusion theory was first met with resistance by some scholars who questioned whether it was distinctive enough to form an independent theory. Whereas identity fusion shares many conceptual features and applications with the social identity

\footnotetext{
${ }^{1}$ In this paper, we use the term "heterogeneity" strictly in the statistical sense, as referring to the variability in size of the association between fusion and outcomes within and between studies.
} 
paradigm (Tajfel et al., 1979; Turner et al., 1987), it differs in some essential respects that might explain its seemingly greater explanatory and predictive power in terms of extreme pro-group outcomes (see Fredman et al., 2015; Gómez \& Vázquez, 2015; Gómez et al., 2019, 2020; Swann \& Buhrmester, 2015; Whitehouse, 2018). Identity fusion theory has various intellectual origins, and the social identity approach is one of them (Swann et al., 2012). Most centrally, it builds on the distinction between social and personal identities at the core of social identity and categorization theories. Also, the Venn diagrams often used to assess identity fusion were previously used in social identity and social categorization research to assess people's relationship of their self to their groups (Schubert \& Otten, 2002).

However, some critical aspects put both theories apart. Arguably most centrally, the social identity paradigm holds that when people engage in pro-group behaviours, they do so not because of their idiosyncratic attributes and individual traits but by adopting the group identity while diminishing their personal identity. Earlier versions of the theory conceptualized the social and personal selves as interacting minimally and personal identity to be largely attenuated in the contexts of groups (Turner et al., 1987). Although newer social identity theory perspectives are less strict about the mutually exclusive nature of personal and social identities (see Hornsey, 2008), identity fusion theory is distinct as it is explicitly based on the synergetic relationship between both. Rather than viewing personal and social selves as separate features of an individual's identity, the theory posits that personal and social identities interact synergistically to enhance pro-group behaviours (Gómez et al., 2011a; but seee Heger et al., 2022).

We demonstrated this principle in experiments in which we activated people's social or personal identities (Gómez et al., 2011a; Swann et al., 2009). In line with the tenet that both identities are functionally equivalent among fused individuals, activating personal identities increased extreme pro-group behaviours to the same extent as activating social 
identities in this group. By contrast, activating personal identities did not significantly affect pro-group orientations among non-fused individuals. Thus, for fused individuals, both identities remain active during social interactions, which enables the channelling of personal agency in favour of group goals. In addition, since identity fusion maintains that individuals can display group behaviours without the abdication of personal identity, both identities promote enhanced dedication to group goals (Swann et al., 2014a).

Furthermore, the interacting identities enable ingroup members to recognize each other, not just in terms of their group membership but also concerning their individual uniqueness and distinctiveness. This notion contrasts with social identity theory, which mainly argues that social identification leads to depersonalization through which people no longer perceive themselves and others as particular individuals but as interchangeable exemplars of the social category (Gómez et al., 2020). For fused individuals, allegiance to the group forms collective ties, and appreciation of individual group members fosters relational ties (Gómez et al., 2019; Swann et al., 2009). This increased cohesion, in turn, is proposed to induce a visceral feeling of being one with the group, where challenges and group issues become personal. We demonstrated how perceptions of collective and overall, relational ties, are inherent to the phenomenon of identity fusion in a series of studies (Gómez et al., 2019).

Another distinctive feature of fusion is its irrevocability, unlike social identification which is regulated by the social context. We provided the first empirical test of this "irrevocability principle," which argues that once an individual has fused with a group, they are likely to experience a sense of irreversible commitment to the group, even in the face of challenges or threats to the group (Vázquez et al., 2017). Considering fusion with the country as the target, the authors examined participants' reactions to three negative historical events (e.g., a corruption scandal involving the Royal Family of Spain). Although average fusion scores declined following these events, the declines were limited to sentiments toward the 
group category - collective ties - but not toward individual group members - relational ties. Moreover, rank orderings of fusion scores remained stable, suggesting that those who were more strongly fused before the events tended to be more strongly fused after them in a relative sense. Strongly fused individuals showed continued commitment to remain in the group and act agentically by fighting and dying for it. These findings demonstrate that negative events weaken some aspects of alignment with the group, including collective ties and fusion, but less so other aspects, such as relational ties and endorsement of pro-group behaviours. Gómez et al. (2019) further investigated degrading collective or relational ties and found that such degradation reduced state but not trait fusion. Together, these findings indicate that some circumstances might reduce identity fusion and/or its consequences temporarily but not permanently, providing empirical evidence for the irrevocability principle.

However, the most marked difference between identity fusion theory and social identity theory may lie in their power to explain the most extreme forms of intergroup outcomes (Gómez et al., 2020). Indeed, social identity theory was initially developed to understand the darker sides of intergroup relations. However, its core construct of social identification often accounts only for milder forms of ingroup favouritism rather than extreme actions such as hostility or willingness to engage in violence against others (Sidanius \& Pratto, 2001; but see Hogg, 2014). Although a comprehensive comparison of the effects of social identification and identity fusion is missing to date, research indicates that identity fusion is factorially distinct and often superior in predicting extreme outcomes such as willingness to fight and die for the group, violent protest, or even the ethnic persecution of outgroups (Bortolini et al., 2018; Gómez et al., 2011a; Kunst et al., 2018, 2019). A recent direct comparison further supported that identity fusion predicts more extreme intergroup 
outcomes (e.g., outgroup hostility), whereas social identification predicts milder outcomes (e.g., prejudice; White et al., 2021).

Notably, identity fusion is not restricted to group categories like social identification is. Generally, identity fusion applies to any situation where an individual interacts with a group (Besta \& Kossakowski, 2018; Gómez et al., 2021; Talaifar \& Swann, 2019), cause (Kunst et al., 2018), religion (Fredman et al., 2017), or non-group entity. For instance, identity fusion can be experienced with other individuals (Gómez et al., 2020; Joo \& Park, 2017; Kunst et al., 2019; Vázquez et al., 2015). In a series of studies, we demonstrated that monozygotic twins show a higher degree of identity fusion than dizygotic twins (Vázquez et al., 2017). This increased fusion explained why monozygotic twins were more willing to sacrifice themselves for each other than dizygotic twins were. In another series of studies, we showed that the most extreme political partisans often experience identity fusion with their political leaders (Kunst et al., 2018). Foreshadowing the storm of the U.S. Capitol in 2021, Republicans who were fused with Donald Trump showed the highest willingness to violently persecute minorities and the political opposition if Trump would advocate for it.

Interestingly, identity fusion has also been demonstrated with outgroups, when people feel sympathy for the outgroups' cause. For example, in a set of studies (Kunst et al., 2018), leftist students, general population individuals, and foreign fighters showed identity fusion with two oppressed groups (i.e., the Palestinian and Kurds). Strikingly, the foreign fighters showed more identity fusion with the Kurds than with their own ethnic groups. Moreover, this identity fusion predicted participants' willingness to engage in violence or even to sacrifice their lives for the respective outgroup.

\section{Identity Fusion and Extreme Pro-Group Outcomes: Remaining Questions}

Although many studies have investigated the nature and the underlying mechanisms related to identity fusion and its effects, answers regarding several central questions remain 
inconclusive and can be profitably addressed through a meta-analysis. First, we aim to investigate the main effect of identity fusion across studies and its susceptibility to publication bias. Second, we are interested in testing whether the basic demographic variables of age and gender can explain some of the variability in results. As most extremism is carried out by young men (Jasko et al., 2022), it is possible that identity fusion predicts extreme pro-group outcomes, especially in samples with many men or young participants. Third, a meta-analysis can provide a robust test of whether measures of identity fusion exhibit greater explanatory power for extreme pro-group orientations than measures of social identification - an issue that has been discussed since the emergence of the field of identity fusion and is yet to be conclusively answered (Gómez et al., 2020).

Fourth, although the role of identity fusion has been tested in various contexts, including countries from five continents (Swann et al., 2014a), whether effect sizes generalize across countries or are culture-dependent has not been systematically examined to date. Specific cultural contexts (i.e., conceptualized at the levels of countries) may cause dynamics that influence the effect of identity fusion on relevant outcomes. For instance, many identity fusion studies, in particular during the first tests of the theory, were conducted in a country that relatively recently emerged from a dictatorship with several competing nationalist movements (i.e., Spain) or a country that experienced increased polarization (i.e., the U.S.). Hence, it is possible that identity fusion may be more strongly associated with extreme pro-group outcomes in factionalized contexts than in contexts with low(er) degrees of intergroup conflict.

Fifth, identity fusion has been tested concerning many qualitatively different groups, such as national (Bortolini et al., 2018; Gómez et al., 2011a; Swann \& Buhrmester, 2015), religious (Besta et al., 2014; Fredman et al., 2017; Gómez et al., 2021, 2022a, 2022b), political (Besta et al., 2015; Buhrmester et al., 2012; Kunst et al., 2019), familial (Vázquez et 
al., 2015), sports supporters (Kossakowski \& Besta, 2018; Newson, 2017; Newson et al., 2018), gang (Gómez et al., 2022a), gender (Gómez et al., 2019), and even outgroups (Kunst et al., 2018). However, it has not been systematically investigated whether its associations with extreme pro-group outcomes differ depending on the group in question. As such, we do not know whether the effects of identity fusion are generalizable or may be more pronounced for some target groups than others (e.g., for local groups in contrast to extended groups; Swann et al., 2012).

Sixth, most studies have reported effects of identity fusion as measured by one of three standard instruments, specifically, the pictorial (Swann et al., 2009), the verbal (Gómez et al., 2011a), and the dynamic (Jiménez et al., 2016) scales. While the three scales are widely applied and accepted, whether results depend on the specific scale used and how robust the effects of each scale are across studies remains to be conclusively answered. Relatedly, identity fusion researchers have used a variety of measures to assess different types of extreme pro-group outcomes. A systematic analysis of these studies can help establish whether the relationship between identity fusion and extreme pro-group outcomes generalizes across identity fusion measurement scales and beyond specific extreme pro-group outcomes. In terms of the latter, we distinguished between three types of extreme outcomes that were identified in a bottom-up categorization when coding the studies: Fight/die/sacrifice (i.e., an extreme reactive/defensive orientation in the case of threat to the group with high personal costs but that is not offensively targeting outgroups; e.g., Atran et al., 2014; Foot, 1967; Gómez et al., 2011a, 2011b; Klein \& Bastian, 2022; Sheikh et al., 2016; Swann et al., 2009, 2010, 2011), extreme collective action (e.g., joining violent protests but with less sacrifice and risk than the fight/die/sacrifice category; Simon \& Grabow, 2010; van Zomeren et al., 2004), and outgroup hostility (e.g., extreme collective action that explicitly and offensively targets outgroups; Altemeyer, 1996; Besta et al., 2014). Is identity 
fusion, in particular, associated with extreme behavioural inclinations that do not necessitate violence against others (i.e., fight or die for the ingroup)? Or are its effects comparable across the different types of outcomes (i.e., behavioural intentions for the ingroup compared to intentions against the outgroup)? These are some of the questions the present meta-analysis of 90 studies with 36,880 participants from nine countries and 106 effects attempted to answer.

\section{Methods}

\section{Inclusion Criteria}

This meta-analysis included published and unpublished studies that reported a statistic (e.g., correlation coefficient, beta estimate, or odds ratio) reflecting the degree of fusion with a group and at least one measure of extreme pro-group orientations. Since its conception (Swann et al., 2009), recent approaches have seen the extension of fusion with a group or a human to other fusion targets (e.g., a brand, a value, and even an animal; Buhrmester et al., 2018). However, most papers to date have investigated the effects of being fused with human targets. Therefore, this meta-analysis focused on fusion with human groups and individuals to investigate the association between fusion and pro-group outcomes.

Extreme pro-group orientations were defined to encompass intentions, behaviour, or attitudinal support for extreme pro-group acts (e.g., willingness to fight, die and sacrifice, political extremism, extreme activism, extreme protest behaviours, or extreme support behaviours). To optimize the selection and coding process, a substantial effort was undertaken to ensure that raters had a shared understanding of this working definition. These efforts included mapping words and concepts in associative networks to help raters converge on a shared understanding prior to the study selection process. 


\section{Search Procedure}

The search for relevant literature followed the PRISMA 2020 guidelines (Page et al., 2021), and was conducted in PsycInfo, Scopus, and Web of Science, in January 2020. The search covered the 2009-2020 timeframe to account for the entire body of literature since the first manuscript on identity fusion was published until the analyses were conducted (Swann et al., 2009). It was structured to capture a wide variety of extreme pro-group outcomes in line with the operationalized definitions of relevant behaviours and attitudes (see Figure 1). The same search string was used for all three databases: (Identity fusion) AND (extrem* OR violen* OR political OR sacrifice OR pro-group). Subsequent steps of literature screening and data structuring were conducted utilizing Cadima, an online synthesis tool for systematic reviews (Kohl et al., 2018). Cadima allows for the automatic exclusion of duplicates. The first author and a research assistant screened unique records at the title, abstract and full-text levels. The interrater agreement was excellent (Cohen's $\kappa=.82)$ for the title and abstract inclusion, and both raters were in perfect agreement (Cohen's $\kappa=1$ ) on the inclusion of eligible records for further analysis.

In parallel with the database search, a call for unpublished data was sent out via the the Society for Personality and Social Psychology list servers and forum. The call resulted in 28 additional studies being included in the analysis. The screening and selection process of unpublished material was performed by the first and second authors based on the same operationalized criteria for extreme pro-group outcomes. Their agreement was perfect (Cohen's $\kappa=1)$. 


\section{Figure 1}

PRISMA Flow-Chart

Identification of Studies via Databases

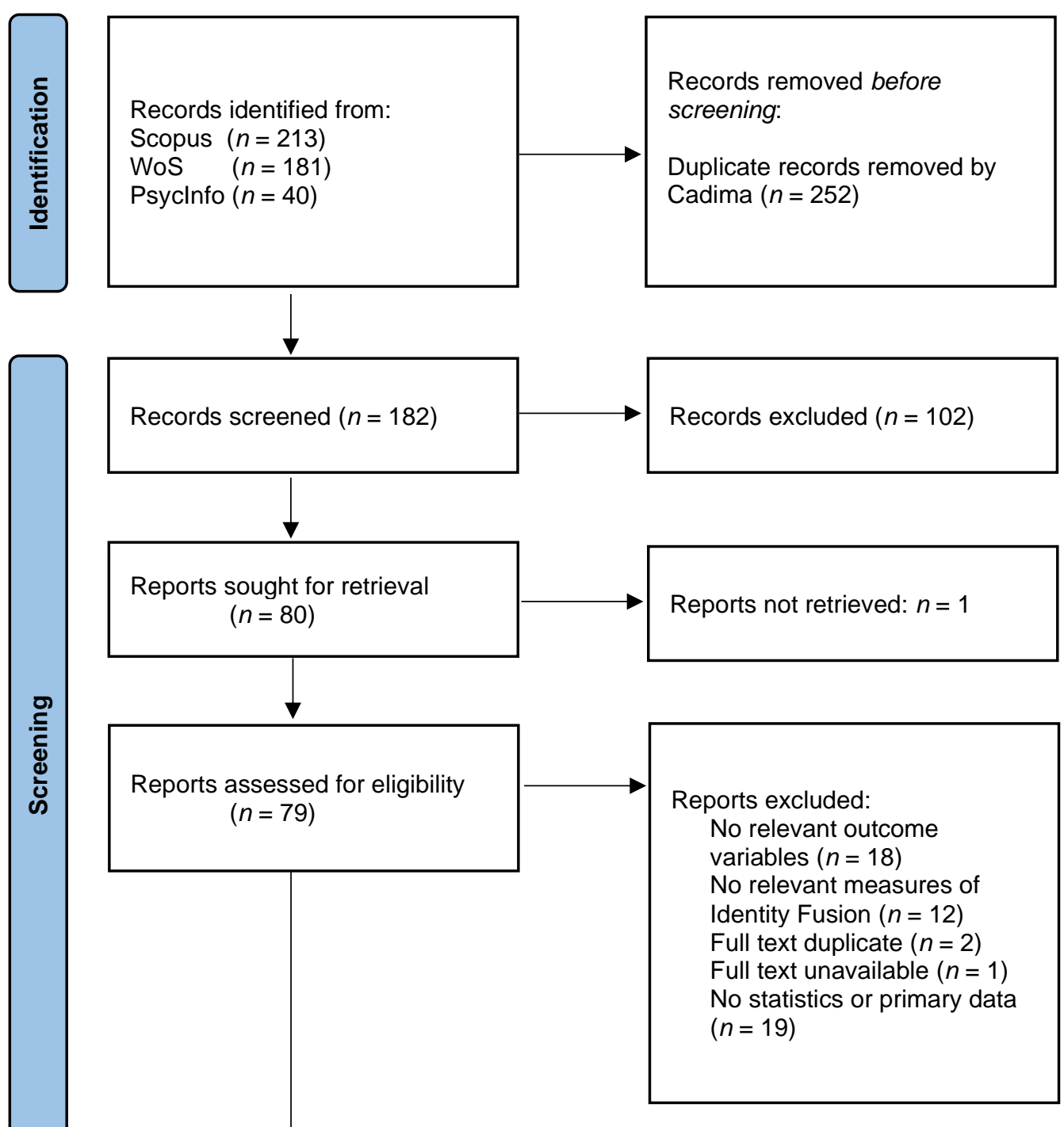

Published reports $(n=27)$

Additional unpublished reports $(n=28)$

Total studies $(\boldsymbol{n}=90)$ 


\section{Coding}

Data from the included records were extracted and coded by the first and second authors, who hold a BA degree or a degree equivalent to the master's level in psychology, respectively. To ensure the consistent and reliable extraction of data, the entire dataset was coded twice. The process resulted in excellent agreement between the two coders (Cohen's $\kappa$ $=.87$ ), and any discrepancies were discussed and recoded separately to ensure consistency.

The following information was extracted from each paper: year of publication, country, sample size, gender and age distribution in the participant sample, identity fusion measurement scale, social identification measurement scale, extreme pro-group outcomes measurement scale, and the number of items of each scale. Correlation coefficients between identity fusion and extreme pro-group outcomes, and social identification and extreme progroup outcomes were extracted whenever available $\left(k_{\text {effects }}=62\right)$. When correlation coefficients were not reported and raw data was not provided or available, correlation coefficients were approximated using the method described in Borenstein et al. (2009) for effects reported as odds-ratios $\left(k_{\text {effects }}=15\right)$ and the formula of Peterson and Brown (2005) for effects reported as regression coefficients $\left(k_{\text {effects }}=21\right)$. The Borenstein (2009) method provides formulas to calculate the standardized mean difference (Cohen's $d$ ) from the odds-ratio, and then calculate the correlation estimate, $r$, from Cohen's $d$. Peterson and Brown (2005) provide evidence that correlation estimates, $r$, can be estimated from beta coefficients with the formula:

$$
r=\beta+(0.05 * \lambda)
$$

where $\lambda=0$ if $\beta<0$ and $\lambda=1$ if $\beta>0$. To assess whether the conversion of estimates induced bias in the estimated averaged effect size, a sensitivity analysis was conducted, regressing the effect size on the type of effect measure (correlation coefficient, odds ratio, or regression coefficient). Results indicated no significant difference in the size of effects 
estimated from correlation coefficients and converted odds-ratios, $B=.03,95 \%$ CI [-.09, $.15]$, or regression coefficients, $B=-.06,95 \%$ CI [-.13, .02].

\section{Sample Descriptives}

The final study pool comprised 90 studies (from 55 reports), including 106 relevant effect sizes from 36,880 participants. Appendix A provides an overview of the included reports, and the full dataset, $\mathrm{R}$ code, and supplementary online materials (SOM) are available via https://osf.io/za4rj/?view_only=3980c9e81fac401e83ce6837f41e4f67. The average sample size was $347.90(S D=377.00)$, and the mean participant age was $33.38(S D=5.73)$. On average, $46.45 \%$ of the participants were men. The primary studies originated from 9 countries, with most effects reported in Spain $\left(k_{\text {effects }}=64\right)$ and the United States $\left(k_{\text {effects }}=21\right)$. Most included studies were cross-sectional.

\section{Analytic Procedures}

The analysis was performed using robust variance estimation (RVE; Hedges et al., 2010) in the R package robumeta v.2.0 (Fisher \& Tipton, 2015; R version 4.6). RVE is a meta-analytic approach that effectively deals with dependency between effect sizes. It has proven to accurately estimate averaged effect sizes even when primary effects are correlated and the correlation size is unknown (Fisher \& Tipton, 2015; Fisher et al., 2017). Prior to analysis, we transformed all effect sizes (Pearson correlations, $r$ ) to Fisher's $z$ for standardization, which allows the calculation of confidence intervals for the correlation coefficients. This transformation normalizes effect sizes so that the sampling distribution approximates the normal distribution assumed by the RVE (Carbonell et al., 2009). Finally, model coefficients and confidence intervals were transformed back to $r$ estimates for reporting and to ensure the interpretability or results (Borenstein et al., 2009), using the standard function in Microsoft Excel. 
Seven meta-regression random-effects RVE models were estimated. One assessed the overall average effect of identity fusion on extreme pro-group orientations. Six tested potential moderating effects on this relationship. In all models, we assumed that the interdependent effects (i.e., effects coming from the same sample) were correlated at $\rho=.80$. To ensure that the assumed correlation did not affect the results, we conducted a sensitivity analysis by estimating the results with $\rho=.0, \rho=.20, \rho=.40, \rho=.60$, and $\rho=1$. We found no differences in the first four digits of the estimate, its standard error and $\tau^{2}$ (see SOM). That is, the assumed correlation size between dependent effects did not affect the results.

First, we fitted an intercept-only model to assess the overall effect size of identity fusion on extreme pro-group outcomes (Model 1). To account for publication bias or other systematic causes of heterogeneity, a precision-effect estimate with standard errors (PETPEESE) analysis was conducted in a sample-size-based variant (Pustejovsky \& Rodgers, 2019). This regression-based method seems to outperform other conventional meta-analytic methods in identifying and reducing publication bias (Stanley, 2017). PET-PEESE consists of two meta-regression models (PET regression and PEESE regression) where the metaanalytical effect is regressed on a transformation of the sample size. The resulting intercept indicates the unbiased effect size, while the regression coefficient reflects the bias. If the intercept of the PET model is significant at $\alpha=.10$, PEESE model results are interpreted; otherwise, PET model results are interpreted (Pustejovsky \& Rodgers, 2019). We supplement these analyses with a funnel plot presented in the SOM.

Next, we tested if the percentage of men in the samples and the mean age of the participants moderated the size of the effects (Model 2). Additionally, we also provide a test of the interaction between both factors. Then, we tested whether the effects of fusion and social identification differed in strength by regressing effect sizes on a dummy moderator 
with effects of social identification coded as 0 and effects of identity fusion coded as 1 (Models 3a and b). Since this test concerns a particularly central question to the field, we estimated the model in two different ways to maximize insights. First, the model was fitted to all studies, giving an overall estimate of the difference between the effects of identity fusion and social identity (Model 3a). Second, we aimed to replicate the results from this model in a more matched selection of studies that measured both constructs to eliminate potential confounding effects due to sample or study variations (Model 3b). We estimated whether effects differ for published and unpublished studies for both models. For Model 3a, we also compared the scales used to measure identity fusion and social identification.

In Model 4, we assessed whether effect sizes of identity fusion differed systematically between countries by including the country of data collection as a categorical moderator. Whereas most studies in the identity fusion literature have been conducted in Spain and the U.S., the articles included in the current meta-analysis comprised studies from nine different countries. This breadth of studies enables investigations as to whether the effects of identity fusion generalize across countries.

In Model 5, we addressed the effect of identity fusion on extreme pro-group outcomes between different group contexts by including the identity fusion target group (country, kinship, religious groups, political groups, outgroup, or other groups) as a categorical moderator. Identity fusion has been applied to explain extreme pro-group orientations in a wide range of group contexts, which may explain some of the variances in the reported estimates. Fusion with some groups may predict more endorsement of extreme behaviour than others.

Model 6 addressed whether the specific scales used to measure identity fusion influenced the size of the meta-analytical effect. The model intercept or reference group represented the effect of the most commonly used verbal identity fusion scale (Gómez et al., 
2011). Finally, Model 7 tested whether the type of extreme pro-group outcome measures moderated the effects. Since most extreme pro-group outcome scales were represented in only a few studies, these were grouped into three categories according to the type of outcome measurement: Fight/Die/Sacrifice, Extreme collective action, and Outgroup hostility, which in terms of individual costs are ordered in descending extremity. The model intercept represented the effect of the most commonly used fight/die/sacrifice scale.

\section{Results}

Model 1 tested the overall association between identity fusion and extreme pro-group orientations. Results showed a strong average correlation across studies (see Table 1, Model 1). Yet, the $I^{2}$ indicated that over $90 \%$ of the variation of the primary effects included in this analysis was due to true variation rather than sampling error, highlighting the need for metaregressions to address potential moderating factors contributing to this variability. However, note that in RVE, the trade-off for high precision in estimating the average effect based on interdependent effects is that heterogeneity estimates are only incidental (Tanner-Smith \& Tipton, 2014). Hence, this method is not suited to assess the true implications of heterogeneity. PET-PEESE analysis exhibited a significant PET intercept $(p<.001)$. Hence, PEESE results were interpreted. Despite significant bias, $B=4.69, p=.046,95 \%$ CI [.08, 9.30], PEESE results revealed a significant unbiased effect comparable in size with the effects of the primary analysis, $r=.46,95 \%$ CI $[.41, .50]$. Note, however, that although stateof-the-art, the PET-PEESE, similar to other existing methods of publication bias assessment, may underperform if $I^{2}>80 \%$ (Stanley, 2017), which was the case here (although, again, RVE. does not allow for reliably assessing heterogeneity; Tanner-Smith \& Tipton, 2014). Because this threshold was largely exceeded in our analyses, PET-PEESE results must be interpreted with caution. To gain additional insights, we conducted a meta-regression to assess whether the effects from published studies systematically differed from those from 
unpublished studies. We found no significant systematic differences in effect size, $B=.02, p$ $=.648,95 \% \mathrm{CI}[-.08, .13]$, supporting the results of the PEESE model. In the funnel plots, the high degree of heterogeneity made it difficult to judge publication bias (see SOM).

Model 2a assessed the moderating effect of mean age and percentage of men on the correlation between identity fusion and extreme pro-group orientations. Results indicated a significant negative yet weak effect of age (standardized for interpretability), suggesting that the effect of identity fusion on extreme pro-group orientations somewhat decreased as the mean age of the sample increased (see Figure 2). No significant effect of gender distribution (\% men) on the effect sizes of identity fusion was observed. However, there was a significant interaction between gender and age in an extended model, $B=-.002, p=.004,95 \%$ CI [-.004, -.001]. The simple slopes presented in SOM showed that the effect of identity fusion on extreme pro-group orientations decreased as age increased in samples with a high percentage of men. This slope was relatively flat for samples with an average or low percentage of men. 
Table 1

Results of Robust Variance Estimation Meta-Analyses

\begin{tabular}{|c|c|c|c|c|c|c|c|c|c|}
\hline Model / Variable & $\begin{array}{c}k \\
\text { effects }\end{array}$ & $\begin{array}{c}k \\
\text { studies }\end{array}$ & Estimate & $\begin{array}{c}95 \% \\
\text { Cl-L }\end{array}$ & $\begin{array}{l}95 \% \\
\mathrm{Cl}-\mathrm{U}\end{array}$ & $p$ & $d f s$ & $R^{2}$ & $\mathrm{~T}^{2}$ \\
\hline Model 1: Main effect & 106 & 90 & & & & & 89 & 90.60 & .03 \\
\hline Intercept (Identity fusion) & & & .495 & .461 & .528 & $<.001$ & & & \\
\hline Model 2: Demographics & 101 & 85 & & & & & 82 & 90.11 & .03 \\
\hline Intercept & & & .508 & .424 & .583 & $<.001$ & & & \\
\hline Men (\%) & & & -.001 & -.003 & .002 & .601 & & & \\
\hline Age & & & -.071 & -.117 & -.024 & .004 & & & \\
\hline $\begin{array}{l}\text { Model 3a: Construct type } \\
\text { (all studies) }\end{array}$ & 138 & 90 & & & & & 88 & 90.80 & .03 \\
\hline \multicolumn{10}{|l|}{ Intercept (Social } \\
\hline identification) & & & .368 & .294 & .438 & $<.001$ & & & \\
\hline Identity fusion & & & .160 & .077 & .238 & $<.001$ & & & \\
\hline $\begin{array}{l}\text { Model 3b: Construct type } \\
\text { (matched studies) }\end{array}$ & 64 & 30 & & & & & 28 & 89.74 & .03 \\
\hline \multicolumn{10}{|l|}{ Intercept (Social } \\
\hline identification) & & & .368 & .290 & .441 & $<.001$ & & & \\
\hline Identity fusion & & & .138 & .086 & .190 & $<.001$ & & & \\
\hline \multirow{2}{*}{$\begin{array}{l}\text { Model 4: Country } \\
\text { Intercept (Spain) }\end{array}$} & 106 & 90 & & & & & 81 & 89.45 & .03 \\
\hline & & & .481 & .438 & .521 & $<.001$ & & & \\
\hline Brazil & & & -.079 & -.177 & .021 & .119 & & & \\
\hline China & & & -.027 & -.081 & .027 & .325 & & & \\
\hline Italy & & & .391 & .342 & .438 & $<.001$ & & & \\
\hline Norway & & & -.014 & -.068 & .040 & .605 & & & \\
\hline Poland & & & .126 & -.096 & .335 & .262 & & & \\
\hline U.K. & & & -.335 & -.382 & -.286 & $<.001$ & & & \\
\hline U.S. & & & .070 & -.057 & .195 & .276 & & & \\
\hline Worldwide & & & -.031 & -.086 & .025 & .271 & & & \\
\hline \multirow{3}{*}{$\begin{array}{l}\text { Model 5: Target group } \\
\text { Intercept (National group) } \\
\text { Kinship }\end{array}$} & 105 & 89 & & & & & 83 & 90.63 & 0.03 \\
\hline & & & .480 & .442 & .516 & $<.001$ & & & \\
\hline & & & -.065 & -.112 & -.017 & .008 & & & \\
\hline Other groups & & & .033 & -.139 & .204 & .705 & & & \\
\hline Outgroup & & & .214 & .052 & .364 & .010 & & & \\
\hline Political group & & & -.122 & -.254 & .013 & .076 & & & \\
\hline Religious group & & & .195 & -.291 & .601 & .431 & & & \\
\hline \multirow{2}{*}{$\begin{array}{l}\text { Model 6: Fusion measure type } \\
\text { Intercept (Identity fusion, } \\
\text { verbal) }\end{array}$} & 105 & 89 & & & & & 86 & 90.40 & 0.03 \\
\hline & & & .519 & .482 & .554 & $<.001$ & & & \\
\hline $\begin{array}{l}\text { Dynamic Identity Fusion } \\
\text { Index (DIFI) }\end{array}$ & & & -.228 & -.376 & -.068 & .006 & & & \\
\hline Pictorial scale & & & -.142 & -.249 & -.032 & .012 & & & \\
\hline Model 7: DV measure type & 101 & 88 & & & & & 85 & 90.33 & 0.03 \\
\hline \multirow{4}{*}{$\begin{array}{l}\text { Intercept } \\
\text { (Fight/Die/Sacrifice) } \\
\text { Extreme Collective action } \\
\text { Outgroup hostility }\end{array}$} & & & & & & & & & \\
\hline & & & .486 & .448 & .522 & $<.001$ & & & \\
\hline & & & .184 & .042 & .318 & .012 & & & \\
\hline & & & -.068 & -.120 & -.016 & .011 & & & \\
\hline
\end{tabular}

Note. Model 1 refers to the main effect of identity fusion on outcomes, whereas Model $2-7$ refer to metaregression models with moderators. Names in parentheses next to the intercept indicate what category was used as baseline in the specific meta-regression. Estimate refers to regression coefficients (back-transformed to $r$ ). ${ }^{a} \mathrm{Age}$ was standardized. ${ }^{\text {b}}$ These analyses were conducted only on studies that measured both identity fusion and social identification. Statistically significant estimates are presented in bold. 
Figure 2

Estimated Effect Size for Models 2 Through 7
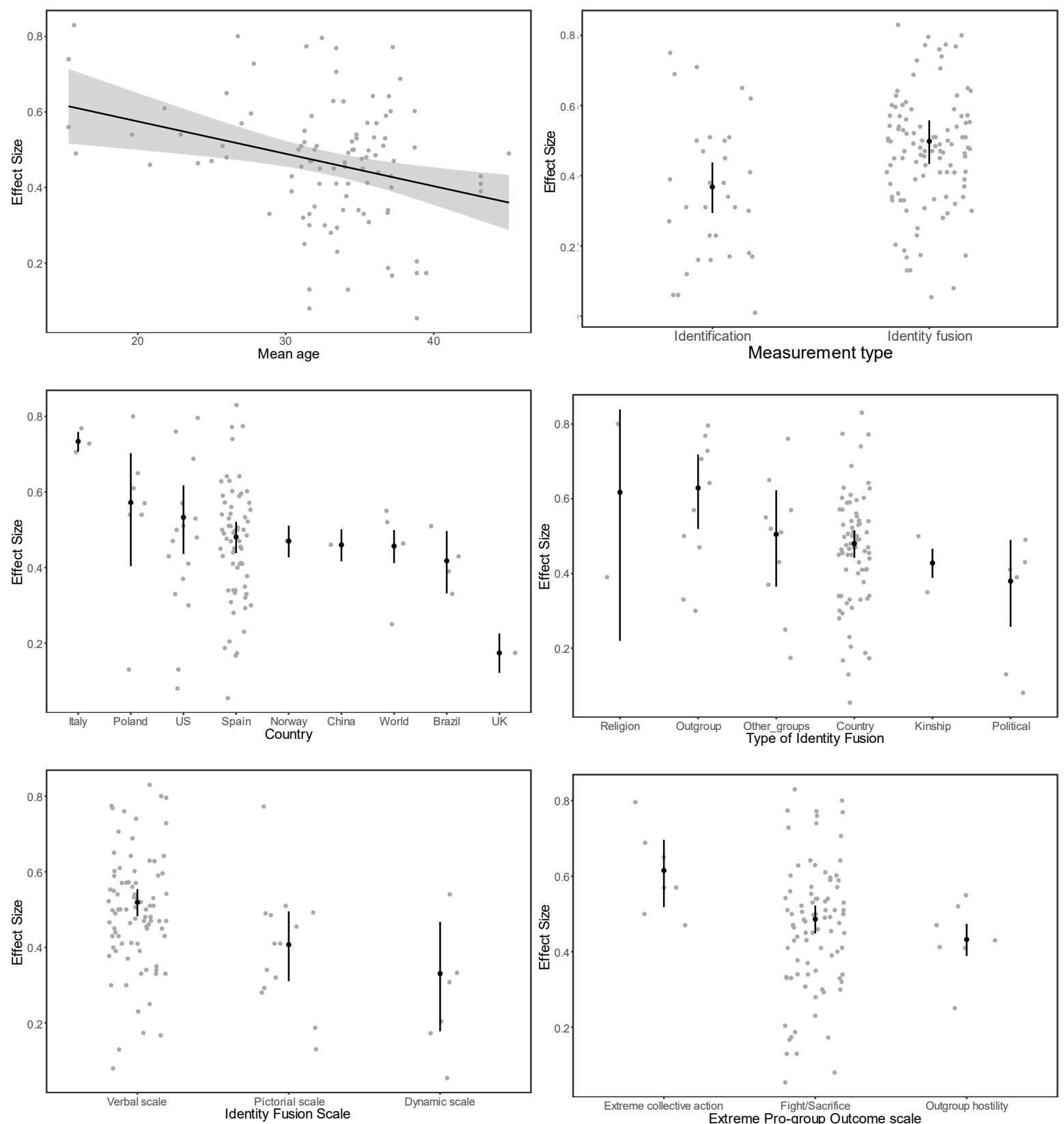

Note. Error bars or ribbons represent $95 \%$ CIs. Black points represent observed mean effects, whereas grey points represent effects for each study. 
Models $3 \mathrm{a}$ and $3 \mathrm{~b}$ tested the difference between the effects of identity fusion and social identification on extreme pro-group orientations using a dummy-coded moderator (identity fusion versus social identification). Results with all studies included indicated a significant difference (see Table 1, Model 3a), where identity fusion, on average, exhibited a stronger association with extreme pro-group outcomes, $r=.50,95 \% \mathrm{CI}[.46, .53], p<.001, I^{2}$ $=90.60$, than social identification, $r=.37,95 \%$ CI $[.29, .44], p<.001, I^{2}=90.36$ (see Figure 2). As this test is particularly relevant to the field, we tested for the role of published versus unpublished studies. The difference between the identity fusion and social identification effects was significant in published studies, $B=.24,95 \%$ CI $[.14, .33], p<.001, I^{2}=90.12$, $k_{\text {studies }}=63, k_{\text {effects }}=94$, but not in unpublished studies, $B=-.01,95 \%$ CI $[-.14, .12], p=.844$, $I^{2}=90.12, k_{\text {studies }}=27, k_{\text {effects }}=44$. We also compared the effects of the different identity fusion and social identification scales (see Table 2). Please note that some of the scales were represented by very few studies. Results therefore must be interpreted cautiously. The verbal identity fusion scale outperformed three of five social identification scales. Notably, its effect was not significantly stronger than that of the social identification scale by Mael and Ashforth (1992), which is most often used for comparisons. The pictorial identity fusion scale performed significantly worse than four out of five social identification measures. The dynamic identity fusion scale performed significantly worse than one of the five social identification scales. 


\section{Table 2}

Results of Robust Variance Estimation Meta-Analyses Comparing Identity Fusion Scales Against Social Identity Measures

\begin{tabular}{|c|c|c|c|c|c|c|c|c|c|}
\hline \multirow[t]{3}{*}{ Reference / Comparison Variables } & \multicolumn{2}{|c|}{$k$} & \multirow[t]{3}{*}{ Estimate } & \multirow{3}{*}{$\begin{array}{c}95 \% \\
\text { Cl-L }\end{array}$} & \multirow{3}{*}{$\begin{array}{l}95 \% \\
\mathrm{Cl}-\mathrm{U}\end{array}$} & \multirow[t]{3}{*}{$p$} & \multirow[t]{3}{*}{$d f s$} & \multirow[t]{3}{*}{$1^{2}$} & \multirow[t]{3}{*}{$\mathrm{T}^{2}$} \\
\hline & & & & & & & & & \\
\hline & studies & effects & & & & & & & \\
\hline Verbal Identity Fusion Scale & 71 & 85 & & & & & 81 & 91.25 & .03 \\
\hline Intercept & - & - & .525 & .477 & .570 & $<.001$ & & & \\
\hline Mael and Ashforth (1992) & 33 & 60 & -.084 & -.185 & .019 & .107 & & & \\
\hline Ellemers et al. (1999) & 2 & 4 & -.255 & -.322 & -.184 & $<.001$ & & & \\
\hline Leach (2008) & 3 & 6 & -.204 & -.283 & -.123 & $<.001$ & & & \\
\hline Postmes (2013) & 1 & 1 & -.021 & -.085 & .044 & .524 & & & \\
\hline Steffens et al. (2015) & 1 & 2 & -.158 & -.220 & -.095 & $<.001$ & & & \\
\hline Pictorial Identity Fusion Scale & 14 & 14 & & & & & 81 & 91.25 & .03 \\
\hline Intercept & - & - & .247 & .158 & .333 & $<.001$ & & & \\
\hline Mael and Ashforth (1992) & 33 & 60 & .242 & .123 & .354 & $<.001$ & & & \\
\hline Ellemers et al. (1999) & 2 & 4 & .070 & -.030 & .168 & .165 & & & \\
\hline Leach (2008) & 3 & 6 & .123 & .016 & .227 & .024 & & & \\
\hline Postmes (2013) & 1 & 1 & .301 & .214 & .383 & $<.001$ & & & \\
\hline Steffens et al. (2015) & 1 & 2 & .170 & .078 & .258 & $<.001$ & & & \\
\hline Dynamic Scale & 4 & 6 & & & & & 81 & 91.25 & .03 \\
\hline Intercept & - & - & .338 & .186 & .473 & $<.001$ & & & \\
\hline Mael and Ashforth (1992) & 33 & 60 & .147 & -.034 & .318 & .110 & & & \\
\hline Ellemers et al. (1999) & 2 & 4 & -.029 & -.193 & .137 & .734 & & & \\
\hline Leach (2008) & 3 & 6 & .025 & -.146 & .194 & .776 & & & \\
\hline Postmes (2013) & 1 & 1 & .208 & .048 & .358 & .012 & & & \\
\hline Steffens et al. (2015) & 1 & 2 & .072 & -.091 & .231 & 381 & & & \\
\hline
\end{tabular}

Note. Please not that all models also included the respective alternative identity fusion scales. These are not included to keep presentation parsimonious. Significant comparisons are presented in bold.

We repeated the comparison between the overall effects of identity fusion and social identification in the subset of matched studies (i.e., only studies reporting both variables). Again, we found a significant difference (see Table 1, Model 3b) with identity fusion having 
a stronger effect, $r=.48,95 \% \mathrm{CI}\left[.42, .54, p<.001, I^{2}=89.04\right.$, than social identification, $r=$ $.37,95 \%$ CI $[.29, .44], p<.001, I^{2}=90.36$. Importantly, this difference was not significantly moderated by whether studies were published or unpublished, $B=-.09,95 \%$ CI $[-.20, .01], p$ $=.084, I^{2}=88.67$.

Model 4 addressed the effect of the country of data collection on the reported effect sizes (see Table 1, Model 4). Results showed significant differences in effect sizes between countries). Specifically, compared to Spain (intercept), $r=.48,95 \%$ CI $[.44, .52], p<.001, I^{2}$ $=89.92, k_{\text {studies }}=57, k_{\text {effects }}=64$, the association between identity fusion and extreme progroup orientations was significantly stronger in Italy, $r=.74,95 \%$ CI $[.66, .80], p<.001, I^{2}=$ $0.00, k_{\text {studies }}=2, k_{\text {effects }}=3$, and significantly weaker in the U.K., $r=.17, k_{\text {studies }}=1, k_{\text {effects }}=$ 1. ${ }^{2}$ However, as a small number of studies represented these countries, results should be interpreted with caution. Even when accounting for variation caused by country, the reported effect sizes still exhibited considerable relative heterogeneity.

Model 5 tested if the effects sizes varied by the target group of identity fusion (e.g., national group, religious group; see Table 1, Model 5, and Figure 2). Results indicated that identity fusion with outgroups had a stronger effect, $r=.62,95 \%$ CI $[.47, .73], p<.001, I^{2}=$ 87.77, $k_{\text {effects }}=8, k_{\text {effects }}=10$, and identity fusion based on kinship a weaker effect, $r=.43$, $k_{\text {studies }}=1, k_{\text {effects }}=2$, compared to identity fusion with a national group, $r=.48,95 \%$ CI [.44, $.51], p<.001, I^{2}=89.07, k_{\text {studies }}=68, k_{\text {effects }}=75$.

Model 6 tested whether effect sizes differed systematically depending on the measurement scale of identity fusion (see Table 1, Model 6, and Figure 2). The most common verbal measure of identity fusion (Gómez et al., 2011a) exhibited an averaged effect size of $r=.52,95 \%$ CI $[.48, .55], p<.001, I^{2}=91.26, k_{\text {studies }}=71, k_{\text {effects }}=85$. This effect was stronger than that of the dynamic identity fusion scale (Jiménez et al., 2016), $r=.33$,

\footnotetext{
${ }^{2}$ Please note that $95 \% \mathrm{Cls}$ or $p$ values cannot be calculated for less than 3 effects.
} 
$95 \%$ CI $[.06, .55], p=.030, I^{2}=79.19, k_{\text {studies }}=4, k_{\text {effects }}=6$, and the pictorial measure by Swann et al. (2009), $r=.41,95 \%$ CI $[.31, .49], p<.001, I^{2}=83.89, k_{\text {studies }}=14, k_{\text {effects }}=14$ (see Figure 2). The latter did not differ significantly, $p=.343$.

Finally, in Model 7, we compared the most common outcome measure used in the identity fusion literature. The willingness to fight/die/sacrifice exhibited an averaged correlation of $r=.49,95 \%$ CI $[.45, .52], p<.001, I^{2}=90.73, k_{\text {studies }}=78, k_{\text {effects }}=87$, which was weaker than the extreme collective action scale, $r=.61,95 \% \mathrm{CI}[.49, .71], p<.001, I^{2}=$ $84.95, k_{\text {studies }}=7, k_{\text {effects }}=7$, but stronger than the outgroup hostility scale, $r=.43,95 \% \mathrm{CI}$ $[.41, .46], p<.001, I^{2}=81.50, k_{\text {studies }}=4, k_{\text {effects }}=7$. No significant difference was observed between effects on the fight/die/sacrifice and the outgroup hostility scales (see Figure 2). We ran additional tests of whether the percentage of men in the studies would moderate these effects, but none of the interactions reached significance, $p s>.246$.

\section{Discussion}

History has shown that individuals can perform extreme actions in favour of their group that seem irrational and go against basic human survival instincts. But why are some individuals willing to perform such actions for their group and others not? What are the psychological dynamics that can potentially explain such behaviour? Identity fusion, conceptualized as a visceral feeling of oneness with a group, is commonly used to explain extreme pro-group orientations. The theory and construct, introduced to the literature about a decade ago, has generated a considerable number of interdisciplinary studies over a relatively short period, including participants from four continents and a large variety of contexts. However, there is substantial variation in how the available literature operationalizes identity fusion and extreme pro-group orientations. This construct variation and its application across various contexts and groups may facilitate the assessments of the validity, generalizability, and applicability of the theory as an explanation for extreme pro-group orientations. Yet, it 
may also lead to high heterogeneity in results. A systematic meta-analysis that can assess this heterogeneity and establish moderators that explain it has been missing to date. By providing such a meta-analysis, we responded to a series of issues central to the theory of identity fusion.

The meta-analysis included 90 studies, more than a hundred effect sizes, and more than thirty-five thousand participants from nine different countries, with four continents represented. While reported effect sizes vary greatly across studies, the general relationship between identity fusion and extreme pro-group orientations is strong, supporting the theoretical predictions and validity of identity fusion.

The results indicated that the effects of identity fusion on extreme pro-group orientations decrease when the mean age of the participants increases. This finding could suggest that identity fusion propels willingness to engage in extreme pro-group behaviours less among older samples. No moderating effect of a study's gender distribution on the effect of identity fusion was observed, but gender interacted significantly with age. When there was a high percentage of men in the studies, the higher the age of participants, the weaker the effects of identity fusion. This finding may suggest that among men, being of young age is a risk factor (cf. Jasko et al., 2022), while it plays less of a role for women. However, it is imperative to note that study-level gender in meta-analyses is more often confounded with other moderating factors than participant-level gender in single studies. This confounding is especially a problem in meta-analyses with a comparably smaller number of studies, such as in the present analysis, where moderators are unequally distributed. For instance, if one compares the studies included in the present meta-analysis, one realizes that those with a low percentage of men in their sample were conducted in different countries and often with different measures and types of fusion than the studies with the highest percentage of men. Interpretations of tests of gender moderation, therefore, have to be made with caution to 
avoid the ecological fallacy of inferring individual-level interactions from study-level variables. Future research may provide a more robust test of the role of study-level gender by asking the authors of these studies to separately estimate the effects of interest among the different gender groups.

In analyses that included all studies, identity fusion was a significantly stronger predictor of extreme pro-group orientations than social identification. However, sensitivity analyses showed that identity fusion had a significantly stronger effect than social identification in published studies but not in unpublished studies. When analysing only the studies that included both measures, which substantially reduces the number of identity fusion effects but creates a more matched comparison, identity fusion also had a stronger effect than social identification. Notably, the latter effect did not differ depending on whether studies were published or unpublished in this subset. Finally, more nuanced analyses suggested that the scales used to measure identity fusion and social identification mattered. The verbal identity fusion scale outperformed most social identification scales other than the one by Mael and Ashforth (1992), which had a very similar effect to identity fusion.

What do these results add to the ongoing debate of whether identity fusion theory is distinct from social identity theory? On the one hand, the overall significant difference between the effects of identity fusion and social identification is consistent with studies suggesting that identity fusion generally outperforms social identification (e.g., Bortolini et al., 2018, Gómez et al., 2011, White et al., 2021). The fact that we find a significant difference between identity fusion and social identification in published but not unpublished studies may have various reasons. Unpublished research may be of lower quality than published work, which may have prevented it from being published. Alternatively, the difference in findings may suggest that studies that found a difference were more likely to be published.. However, analyses with the matched subset of studies that included both identity 
fusion and social identification measures corroborated these results. Here, identity fusion had a more substantial effect than social identification, irrespective of publication status. The analysis with this subset has the advantage of allowing for effects comparisons with the same target groups and dependent outcomes assessed within the same contexts, reducing both error and heterogeneity due to other factors than the measured constructs. In sum, our results support the superior predictive power of identity fusion, with some nuances.

To gain additional insights, we also compared the identity fusion measures to the different social identification scales using the full dataset to ensure adequate power. Here, the verbal identity fusion scale had better predictive validity than three out of five subscales, whereas the other (single-item) dynamic and pictorial identity fusion scales performed similarly or worse. It is important to note that social identification scales other than the scale by Mael and Ashforth (1992) were represented by a low number of studies. We, therefore, focus our discussion on this scale here. The fact that the verbal identity fusion scale was not superior to the social identification scale by Mael and Ashforth (1992) in predicting extreme outcomes may be interpreted in two ways - one that is favourable for the theory of identity fusion and another that is unfavourable for it.

The favourable interpretation would be that the social identification scale by Mael and Ashforth goes far beyond typical measures of social identification and, in fact, comes close to measuring identity fusion. For instance, items include, "When someone criticizes [group], it feels like a personal insult," "When someone praises my [group], it feels like a personal compliment," and “This [group]'s successes are my successes” (Mael \& Ashforth, 1992). It could be argued that these items measure a sense of overlap between the personal self and the group, however, in a less explicit manner than the items of identity fusion scales.

Alternatively, one could argue that they measure the consequences of strong self-group overlap rather than social identification per se. Thus, while the broader theories differ more 
notably, it is not readily evident whether the scales measure qualitatively (i.e., distinct experiences) rather than quantitatively (i.e., stronger degrees of) different self-group overlap. In other words, one could argue that, although the scale by Mael and Ashforth is usually referred to as a social identification scale, it measures a construct closer to identity fusion than social identification, which may explain the non-significant differences.

An interpretation less favourable for identity fusion theory would be that the scale by Mael and Ashforth (1992) simply reflects a social identification scale that is matched with the identity fusion scale in terms of the extremity of wording. The non-significant differences between this social identity scale and the verbal identity fusion scale may then lead to two conclusions. Identity fusion and social identification are simply comparably predictive of extreme intergroup outcomes when measured at the same level of verbal extremity. This conclusion would make them complementary predictors in this type of research.

Alternatively, it could be argued that identity fusion and social identification reflect the same construct. Echoing such a conclusion, researchers such as Vignoles (2018) have criticized that "a visceral feeling of 'oneness' with the group (...) is conceptually at the heart of the identification construct as defined here, but it has been represented in empirical research as a separate construct" (p. 3). In any case, it is essential to note that psychometric scales only assess specific constructs of larger and more complex psychological theories. Thus, the results do not necessarily lend themselves to conclusions that identity fusion theory provides a better or worse explanation of extreme pro-group behaviour than social identity theory. Clearly, the results from our meta-analysis emphasise the continued importance of future research to address this ongoing debate that is of high conceptual and empirical importance for the theories of identity fusion, social identity, and their intersections.

The relationship between fusion and pro-group orientations differed across countries. However, only a very limited number of studies were conducted outside Spain and the U.S. 
during the time period considered for the meta-analyses. Thus, these differences should be interpreted cautiously, considering the possibly limited precision of the meta-analytical effects observed in other countries. The cases of Italy and the U.K. should for now be regarded as possible outliers given the small number of observations. The two countries that were covered by the most effects (i.e., Spain and the U.S.) converged remarkably in the estimated effect size, despite their very different historical and socio-political backgrounds. Thus, as the number of studies increases in the countries represented by only a few studies, the effect size will likely get closer to that observed in the contexts currently better represented in the available research.

Further, the variation of measurement instruments used across cultures limits the conclusions one can draw from comparisons between studies in a meta-analysis with relatively few and unevenly distributed effects. As such, more research from diverse cultural contexts using the same measurement scales is needed. One potential hypothesis here could be that countries characterized as highly collectivistic might exhibit more potent effects of identity fusion than countries characterized as highly individualistic. In highly collectivistic cultures like Japan and China, individuals' self-concepts are largely comprised of social relationships and group memberships (Triandis, 1988). By contrast, highly individualistic cultures like the U.S., to a much larger extent foster independent self-concepts. It seems intuitive that collectivistic cultures thus might induce stronger tendencies of identity fusion and action on behalf of a group. However, although identity fusion may be more prevalent in collectivistic cultures, this does not necessarily mean it would also cause more extreme progroup behaviour. Thus, systematically assessing such potential differences may provide insights into the role of culture, which could greatly benefit the development of the identity fusion paradigm. 
Identity fusion with an outgroup had a significantly stronger effect on extreme progroup orientations than fusion with the country (i.e., participants' country of residence or national group). Here, outgroup refers to a group of individuals that one de facto is not part of but feels strong solidarity for (e.g., leading one to engage in extreme activism in support of others' political struggles; Kunst et al., 2018). One explanation could be that empathy and solidarity are strong drivers of the effect of identity fusion because individuals sometimes might experience more solidarity with oppressed outgroups than with a group that they consider themselves a part of. Arguably, for people to fuse with an outgroup, a higher degree of emotional involvement or possibly admiration (Gómez et al., 2021) may be needed than for fusion with a group one was born into or belonged to for long periods (i.e., one's nation). Such emotional involvement and perceived importance may also have explained why identity fusion with another gender group in a previous study predicted intentions to change one's sex surgically and whether participants went through with the surgery (Swann et al., 2015). It is also possible that fusion with outgroups functions as "politicized" identity fusion and, thereby, is a better predictor of extreme pro-group orientations than other forms of identity fusion (similar to politicized social identities; van Zomeren et al., 2008). Further studies should address such dynamics by investigating the moderators of identity fusion with ingroups and outgroups of various kinds.

Next, the present analysis addressed whether the effects of fusion depended on how it was measured. Whereas all scales exhibited a significant effect on extreme pro-group orientations, the measurement choice influenced the effects' strength. The verbal scale yielded significantly stronger effects than the pictorial and dynamic scales, which both had similar effects. However, considering the relatively low number of studies conducted with the dynamic and pictorial scales, results should be interpreted cautiously. Generally, the different scales are represented unevenly in the literature. Therefore, further studies measuring identity 
fusion in the same sample using all three measurement scales are warranted to solidify our findings regarding their predictive ability.

The effects of identity fusion varied with the type of extreme pro-group outcome assessed. Generally, identity fusion was more strongly associated with extreme collective action than the willingness to fight and sacrifice or extreme outgroup hostility. An explanation for this finding may be that in studies of extreme collective action, the focus group is usually politicized and, therefore, arguably, more action-oriented. By contrast, in studies assessing willingness to fight/die, the focus group was mainly one's country. However, it is essential to note that only a few studies have been conducted with extreme collective action or outgroup hostility compared to sacrifice/die, rendering the estimated average effects unstable. Further, studies conducted with fight and sacrifice outcomes yielded high heterogeneity.

\section{Constraints on Generality}

While the results presented in this meta-analysis provided a robust assessment of the association between identity fusion and extreme pro-group outcomes, some critical methodological limitations should be noted. First, although the meta-analysis assessed fusion effects measured in various settings, most studies in the literature were conducted in a smaller selection of WEIRD countries (Henrich et al., 2010). As such, we could not systematically test with adequate power for the influence of country-level variables, which may help explain the large heterogeneity. Generally, it is important to note that, although many moderators were significant, they could not meaningfully reduce the observed heterogeneity of effects that was very high according to common standards (Ioannidis, 2008). While this high heterogeneity was expected due to the varied applications of identity fusion theory in existing research, we had also expected that moderators related to contexts and measurement would explain more of this heterogeneity. The persistently high heterogeneity suggests that 
unobserved macro-level variables may critically shape the nature of identity fusion. Future, large-scale cross-cultural studies may therefore provide important insights into the conditions that favour extreme pro-group outcomes. For instance, it may be possible that the level of factionalization and conflict in a society determines the degree to which identity fusion is linked to such outcomes. Especially conditions of conflict and threat may activate the negative potential of identity fusion, whereas this potential may be dormant in peaceful and calm environments. Economic inequality is also known to be a catalyst of extremism (Kunst et al., 2017), which in turn is indicative of the stability of society (Wilkinson, 2015). Particularly under conditions of economic scarcity or when existing social hierarchies are threatened, identity fusion with extreme political groups and leaders may fuel extreme outcomes (Kunst et al., 2019; also see Jetten \& Mols, 2021).

Second, a limitation of the current study is that some of the effects included were conversions of correlation coefficients from either beta coefficients or odds-ratio estimates. While Peterson and Brown (2005) present compelling evidence supporting the high correlation between beta coefficients and correlation coefficients regardless of the number of model parameters, other authors argue that averaging across regression effect sizescan be problematic generally (Becker \& Wu, 2007). While our analysis showed no significant differences between these types of effects and both conversion methods are commonly used, it cannot be conclusively determined whether the conversion procedure altered the actual effects of the respective studies.

An additional methodological limitation concerns using the PET-PEESE test as a test of publication bias. While PET-PEESE consistently outperforms conventional methods to address publication bias (Stanley, 2017), simulation studies show that it is sensitive to heterogeneity in the sample. With high levels of heterogeneity, the PET-PEESE tends to become type I error inflated (Stanley, 2017). Hence, findings must be interpreted with 
caution if the model $I^{2}$ exceeds a value of .80, which was the case for all models in the present meta-analysis. However, this problem is much worse in other methods that test for publication bias (Stanley, 2017), rendering the PET-PEESE the best available option. Additionally, a regression analysis testing the effect of published versus unpublished articles showed no significant differences for the main effect, although some publication bias may have been evident in the comparison between identity fusion and social identification effects.

While identity fusion theory aims to explain extreme pro-group behaviours, the measurement scales included in this meta-analysis typically assess intentions or willingness to engage in behaviours. Hence, whether individuals would perform such extreme pro-group actions (e.g., sacrificing one's life for the group) remains impossible to measure for practical and ethical reasons. However, our recent results indicating that jihadists in prisons express higher levels of fusion and engage in more costly sacrifices than Muslims imprisoned for crimes unrelated to terrorism support the ecological validity of identity fusion (Gómez et al., 2021, 2022a, 2022b). Other examples supporting the predictive validity of fusion with a group have been found among Libyan insurgents fighting against the Gaddafi regime (Whitehouse et al., 2014), captured ISIS fighters (Gómez et al., 2017), Pakistani participants supporting the Kashmiri cause (Pretus et al., 2019), supporters of an Al Qaeda associated group (Hamid et al., 2019), Northern Irish loyalist and republican paramilitaries (Ferguson \& McAuley, 2020), and fighters against the Islamic State including Peshmerga, Iraqi army Kurds, Arab Sunni Militia (Gómez et al., 2017) and foreign fighters (Kunst et al., 2018). Whereas some of these studies were part of the present meta-analysis, others did not psychometrically assess both identity fusion and extreme outcomes and therefore fell outside the inclusion criteria. Future meta-analyses may focus on different topics (i.e., compare the mean identity fusion level between extremist and general population groups) with broader inclusion criteria that will result in the inclusion of more studies from non-WEIRD contexts. 
In any case, as most studies have primarily assessed extreme pro-group outcomes with selfreport scales, the meta-analytic results must be interpreted accordingly. Future research may therefore profit from assessing the consequences of identity fusion using behavioural outcomes.

An additional issue of the available literature is the reliance on cross-sectional data, which reduces the ability to disentangle cause and effect, as no temporal or causal relationship can be investigated. Thus, correlations between the two constructs in the present meta-analysis could, in theory, be purely spurious and induced by an unmodelled common cause (i.e., a third variable that causes both individuals to experience identity fusion and commit extreme pro-group behaviours). The field would therefore benefit from an increased focus on longitudinal studies that address the temporal relationship between the two constructs. In addition, developing and validating new experimental procedures to manipulate identity fusion could provide essential insights into the actual causal effects of identity fusion on extreme pro-group orientations. Evidence indicates that effect sizes in meta-analyses generally tend to decrease when assessed with experimental or longitudinal data compared to observational cross-sectional data (Bierwiaczonek \& Kunst, 2021). Hence, the strong average effect of identity fusion observed in the present meta-analysis is likely inflated.

\section{Conclusion}

Scholars have productively researched identity fusion's role in explaining extreme pro-group orientations over the past decade. This first meta-analysis on the topic demonstrated that identity fusion tends to be strongly associated with different types of extreme pro-group outcomes. Furthermore, its effect is stronger than that of social identification, although this difference is less prevalent in unpublished work. Further, results showed that the association between identity fusion and extreme outcomes was moderated by age (including its interaction with gender), country of data collection, the target group of 
identity fusion, and how both identity fusion and extreme pro-group outcomes were measured. However, as many of the moderators were represented by a few studies, these results should be interpreted cautiously, urging the need for future research. Given the maturity that the field of identity fusion has reached, and the effect heterogeneity that remained very high after the inclusion of various moderators, especially large-scale crosscultural studies including non-Western countries may be well-positioned to identify macrolevel moderators of the effect of identity fusion on extreme pro-group orientations. Moreover, given the primary reliance of researchers on correlational self-report data in a field that aims to explain the causal drivers of extreme behaviours, more experimental and longitudinal work with behavioural outcomes is needed.

\section{Appendix A}

Main Characteristics of Studies Included in the Meta-Analysis

\begin{tabular}{|c|c|c|c|c|c|c|c|c|}
\hline Author & Year & Country & & Male (\%) & Mean age & Fusion scale & Outcome scale & Fusion type \\
\hline \multirow[t]{2}{*}{ Besta et al. } & 2014 & Poland & 109 & 44.00 & 27.76 & Verbal & Fight and die & Religion \\
\hline & 2014 & Poland & 365 & 46.00 & 21.84 & Verbal & Fight and die & Country \\
\hline Besta & 2014 & Poland & 203 & 69.00 & 34.20 & Pictorial & Fight and die & Country \\
\hline \multirow[t]{2}{*}{ Besta et al. } & 2015 & Poland & 155 & 52.26 & 19.60 & Verbal & Fight and die & Country \\
\hline & & Poland & 24 & 91.67 & 22.90 & Verbal & Fight and die & Country \\
\hline Besta \& Kossakowski & 2018 & Poland & 568 & 88.56 & 27.02 & Verbal & Collective action & Other groups \\
\hline \multirow[t]{3}{*}{ Bortolini et al. } & 2018 & Brazil & 387 & 45.20 & 28.90 & Verbal & Fight and die & Country \\
\hline & & Brazil & 372 & 33.30 & 30.40 & Verbal & Fight and die & Religion \\
\hline & & Brazil & 401 & 47.60 & 30.40 & Verbal & Fight and die & Other groups \\
\hline \multirow[t]{2}{*}{ Buhrmester et al. } & 2015 & U.S. & 80 & 38.00 & 26.00 & Verbal & Support actions & Country \\
\hline & & U.S. & 120 & 46.00 & 37.30 & Verbal & Fight/die/sacrifice & Country \\
\hline
\end{tabular}




\begin{tabular}{|c|c|c|c|c|c|c|c|c|}
\hline & & U.S. & 133 & 42.00 & 34.00 & Verbal & Donations, Support actions & Country \\
\hline Carnes \& Lickel & 2018 & U.S. & 204 & 41.70 & 35.44 & Verbal & Fight and die & Country \\
\hline Chinchilla et al. & Unpublished & Spain & 338 & 43.20 & 35.59 & Verbal & Fight/die/sacrifice & Country \\
\hline Chinchilla et al. & Unpublished & Spain & 321 & 64.50 & 38.72 & Verbal & $\begin{array}{l}\text { Fight/die/sacrifice, Costly } \\
\text { sacrifice }\end{array}$ & Country \\
\hline Chinchilla et al. & Unpublished & Italy & 114 & 66.70 & 33.42 & Verbal & $\begin{array}{l}\text { Collective action, Fight and } \\
\text { die }\end{array}$ & Outgroup \\
\hline Chinchilla et al. & Unpublished & Italy & 78 & 27.20 & 27.85 & Verbal & Collective action & Outgroup \\
\hline Chinchilla et al. & Unpublished & Spain & 197 & 36.50 & 36.97 & Verbal & Collective action & Outgroup \\
\hline Chinchilla et al. & Unpublished & Spain & 424 & 46.70 & 35.52 & Verbal & $\begin{array}{l}\text { Fight/die/sacrifice, Outgroup } \\
\text { hostility }\end{array}$ & Country \\
\hline Chinchilla et al. & Unpublished & Spain & 424 & 36.00 & 31.76 & Verbal & $\begin{array}{l}\text { Fight/die/sacrifice, Outgroup } \\
\text { hostility }\end{array}$ & Country \\
\hline \multirow[t]{3}{*}{ Gómez et al. } & 2011a & Spain & 86 & 36.05 & 33.42 & Pictorial & Fight and die & Country \\
\hline & & Spain & 460 & 19.13 & 32.10 & Pictorial & Fight and die & Country \\
\hline & & Spain & 194 & 21.13 & 34.22 & Pictorial & Fight and die & Country \\
\hline \multirow[t]{7}{*}{ Gómez et al. } & $2011 b$ & Spain & 620 & 27.00 & 32.64 & Verbal & Fight and die & Country \\
\hline & & Spain & 92 & 42.40 & 33.88 & Verbal & Fight/die/sacrifice & Country \\
\hline & & Spain & 93 & 49.50 & 34.09 & Verbal & Fight/die/sacrifice & Country \\
\hline & & Spain & 79 & 15.20 & 31.05 & Verbal & Fight and die & Country \\
\hline & & Spain & 37 & 13.50 & 30.86 & Verbal & Fight and die & Country \\
\hline & & U.S. & 357 & 33.00 & 34.79 & Verbal & Fight and die & Country \\
\hline & & Spain & 1981 & 28.00 & 31.64 & Verbal & Fight and die & Country \\
\hline \multirow[t]{2}{*}{ Gómez et al. } & 2019 & Spain & 1151 & 37.00 & 37.11 & Verbal & Fight and die & Country \\
\hline & & Spain & 458 & 41.00 & 37.14 & Verbal & Fight and die & Country \\
\hline \multirow[t]{2}{*}{ Heger \& Gaertner } & 2018 & U.S. & 190 & 46.00 & NA & Verbal & Fight and die & Other groups \\
\hline & & U.S. & 189 & 43.00 & NA & Verbal & Fight and die & Other groups \\
\hline Jiménez et al. & 2016 & Spain & 95 & 20.00 & 34.78 & Dynamic & Fight and die & Country \\
\hline Kavanagh et al. & 2019 & World & 605 & 95.40 & 31.27 & Verbal & Outgroup prejudice & Other groups \\
\hline Kossakowski \& Besta & 2018 & Poland & 309 & 87.40 & 26,00 & Verbal & Extreme endorsement & Other groups \\
\hline \multirow[t]{4}{*}{ Kunst et al. } & 2018 & Norway & 215 & 40.90 & 24.99 & Verbal & Extreme protest & Outgroup \\
\hline & & U.S. & 201 & 56.70 & 34.60 & Verbal & Extreme protest & Outgroup \\
\hline & & U.S. & 234 & 45.70 & 36.13 & Verbal & Extreme protest & Outgroup \\
\hline & & U.S. & 83 & 96.30 & 31.60 & Verbal & Fight/die/sacrifice & Outgroup, Country \\
\hline \multirow[t]{2}{*}{ Kunst et al. } & 2019 & U.S. & 176 & 41.50 & 43.19 & Verbal & $\begin{array}{l}\text { Political extremism, Policy } \\
\text { support }\end{array}$ & Political \\
\hline & & U.S. & 171 & 49.80 & 43.18 & Verbal & Political extremism & Political \\
\hline
\end{tabular}




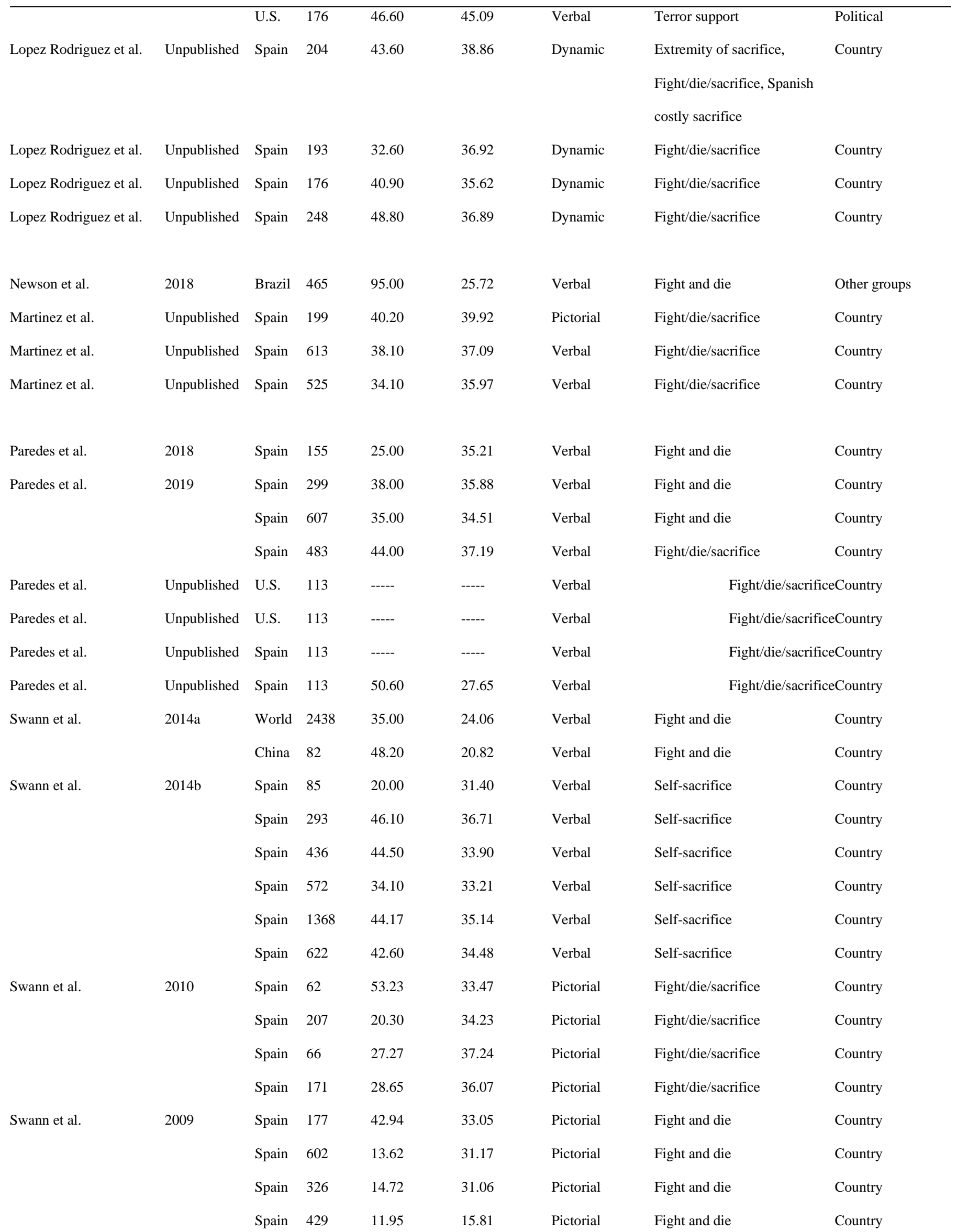




\begin{tabular}{|c|c|c|c|c|c|c|c|c|}
\hline Talaifar \& Swann & 2019 & U.S. & 303 & 44.60 & 36.60 & Verbal & Fight and die & Country \\
\hline Vázquez et al. & 2015 & Spain & 1522 & 41.60 & 32.28 & Verbal & Fight and die & Country \\
\hline Vázquez et al. & 2019 & Spain & 248 & 41.00 & 31.95 & Verbal & Fight and die & Kinship \\
\hline Vasquez et al. & Unpublished & Spain & 193 & 51.80 & 15.32 & Verbal & Fight/die/sacrifice & Country \\
\hline Vasquez et al. & Unpublished & Spain & 111 & 54.90 & 15.52 & Verbal & Fight/die/sacrifice & Country \\
\hline Vasquez et al. & Unpublished & Spain & 122 & 49.10 & 15.70 & Verbal & Fight/die/sacrifice & Country \\
\hline Vasquez et al. & Unpublished & Spain & 109 & 34.80 & 34.92 & Verbal & Fight/die/sacrifice & Country \\
\hline Vasquez et al. & Unpublished & Spain & 1245 & 40.20 & 35.27 & Verbal & Fight/die/sacrifice & Country \\
\hline Vasquez et al. & Unpublished & Spain & 792 & 35.40 & 33.48 & Verbal & Fight/die/sacrifice & Country \\
\hline Vasquez et al. & Unpublished & Spain & 355 & 41.40 & 36.78 & Verbal & Fight/die/sacrifice & Country \\
\hline Vasquez et al. & Unpublished & Spain & 250 & 44.80 & 32.31 & Verbal & Fight/die/sacrifice & Country \\
\hline Vasquez et al. & Unpublished & Spain & 308 & 46.80 & 33.24 & Verbal & Fight/die/sacrifice & Country \\
\hline Vasquez et al. & Unpublished & Spain & 806 & 38.80 & 36.24 & Verbal & Fight/die/sacrifice & Country \\
\hline \multirow[t]{2}{*}{ Whitehouse et al. } & 2017 & U.S. & 122 & 46.20 & 37.74 & Verbal & Extreme endorsement & Country \\
\hline & & U.K. & 725 & 88.90 & 39.50 & Verbal & Fight and die & Other groups \\
\hline
\end{tabular}

\section{Acknowledgement \& Funding}

We thank Dinh Hung Vu for assisting in the coding of the studies. J.R.K. was supported by an EEA Norway Grants, 2020-2024 for the project APVIOLEXT (PL-Basic Research-0011). A.V. was supported by grant PID2021-126085OB-I00, funded by the Ministry of Science, Innovation, and Universities of Spain. A.G. was supported by ERC Advanced Grant, Agreement nr. 101018172, A Multi-Theory Approach for Preventing and Reducing Radicalization leading to violence-MULTIPREV, and grant PID2021-124617OB-I00 from the Spanish Ministry of Science and Innovation. 


\section{Disclosure Statement}

The authors report there are no competing interests to declare.

\section{Author Contributions}

A.H.V., J.R.K., L.K., and K.B. designed the study. A.H.V. and L.K. conducted the literature search and coded the studies. K.B., J.R.K., L.K., and A.H.V. analysed the data. A.H.V., J.K., L.K. and K.B. drafted and revised the first version of the manuscript. A.G. and A.V. provided critical feedback and revisions. J.R.K., K.B., and A.G. revised the manuscript. A.V., A.H.V. and L.K. provided critical feedback. 


\section{References}

Altemeyer, R. A., \& Altemeyer, B. (1996). The authoritarian specter. Harvard University Press.

Atran, S., Sheikh, H., \& Gómez, A. (2014). For cause and comrade: Devoted actors and willingness to fight. Cliodynamics: The Journal of Quantitative History and Cultural Evolution, 5(1), 41-57. https://doi.org/10.21237/c7clio5124900

Atran, S. (2021). Psychology of Transnational Terrorism and Extreme Political Conflict. Annual Review of Psychology, 72(1), 471-501. https://doi.org/10.1146/annurev-psych010419-050800

Becker, B. J., \& Wu, M. J. (2007). The synthesis of regression slopes in meta-analysis. Statistical science, 22(3), 414-429. https://doi.org/10.1214/07-STS243

Besta, T. (2014). Overlap between personal and group identity and its relation with radical pro-group attitudes: Data from a Central European cultural context [Group \& Interpersonal Processes 3020]. Studia Psychologica, 56(1), 67-81. https://doi.org/10.21909/sp.2014.01.651

Besta, T., Gómez, Á., \& Vázquez, A. (2014). Readiness to deny group’s wrongdoing and willingness to fight for its members: The role of poles' identity fusion with the country and religious group. Current Issues in Personality Psychology, 2(1), 49-55. https://doi.org/10.5114/cipp.2014.43101

Besta, T., \& Kossakowski, R. (2018). Football supporters: Group identity, perception of ingroup and outgroup members and pro-group action tendencies. Revista De Psicologia Del Deporte, 27(2), 15-22. 
Besta, T., Szulc, M., \& Jaśkiewicz, M. (2015). Political extremism, group membership and personality traits: who accepts violence? / Extremismo político, pertenencia al grupo y rasgos de personalidad: ¿Quién acepta la violencia? Revista De Psicologia Social, $30(3), 563-585$.

https://doi.org/10.1080/02134748.2015.1065085

Bierwiaczonek, K., \& Kunst, J. R. (2021). Revisiting the integration hypothesis: Correlational and longitudinal meta-analyses demonstrate the limited role of acculturation for cross-cultural adaptation. Psychol Sci, 32(9), 1476-1493. https://doi.org/10.1177/09567976211006432

Borenstein, M., Cooper, H., Hedges, L., \& Valentine, J. (2009). Effect sizes for continuous data. In H. Cooper, L. V. Hedges, \& J. C. Valentine (Eds), The handbook of research synthesis and meta-analysis (2nd ed., pp. 221-235). Russel Sage Foundation.

Bortolini, T., Newson, M., Natividade, J. C., Vázquez, A., \& Gómez, A. (2018). Identity fusion predicts endorsement of pro-group behaviours targeting nationality, religion, or football in Brazilian samples. British Journal of Social Psychology, 57(2), 346-366. https://doi.org/10.1111/bjso.12235

Buhrmester, M. D., Gómez, Á., Brooks, M. L., Morales, J. F., Fernández, S., \& Swann, W. B. (2012). My group's fate is my fate: Identity-fused Americans and Spaniards link personal life quality to outcome of 2008 elections. Basic and Applied Social Psychology, 34(6), 527-533. https://doi.org/10.1080/01973533.2012.732825

Buhrmester, M. D., Fraser, W. T., Lanman, J. A., Whitehouse, H., \& Swann, W. B. (2015). When terror hits home: Identity fused Americans who saw Boston Bombing victims as "family" provided aid. Self and Identity, 14(3), 253-270. https://doi.org/10.1080/15298868.2014.992465 
Buhrmester, M. D., Burnham, D., Johnson, D. D., Curry, O. S., Macdonald, D. W., \& Whitehouse, H. (2018). How moments become movements: Shared outrage, group cohesion, and the lion that went viral. Frontiers in Ecology and Evolution, 6, 54. https://doi.org/10.3389/fevo.2018.00054

Carbonell, P., Rodríguez-Escudero, A. I., \& Pujari, D. (2009). Customer involvement in new service development: An examination of antecedents and outcomes. Journal of product innovation management, 26(5), 536-550. https://doi.org/10.1111/j.15405885.2009.00679.x

Carnes, N. C., \& Lickel, B. (2018). Moral binding: How emotions, convictions, and identity fusion shape progroup behavior. Self and Identity, 17(5), 549-573. https://doi.org/10.1080/15298868.2018.1451362

Ferguson, N., \& McAuley, J. W. (2020). Staying engaged in terrorism: narrative accounts of sustaining participation in violent extremism. Frontiers in Psychology, 11, 1338. https://doi.org/10.3389/fpsyg.2020.01338

Fisher, Z., Bollen, K., Gates, K., \& Rönkkö, M. (2017). MIIVsem: Model implied instrumental variable (MIIV) estimation of structural equation models. $R$ package version $0.5,2$.

Fisher, Z., \& Tipton, E. (2015). robumeta: An R-package for robust variance estimation in meta-analysis. Preprint. https://doi.org/10.48550/arXiv.1503.02220

Foot, P. (1967). The problem of abortion and the doctrine of the double effect. Oxford review, 5 .

Fredman, L. A., Bastian, B., \& Swann, W. B. (2017). God or country? Fusion with Judaism predicts desire for retaliation following Palestinian stabbing Intifada. Social Psychological and Personality Science, 8(8), 882-887. https://doi.org/10.1177/1948550617693059 
Fredman, L. A., Buhrmester, M. D., Gómez, A., Fraser, W. T., Talaifar, S., Brannon, S. M., \& Swann Jr, W. B. (2015). Identity fusion, extreme pro-group behavior, and the path to defusion. Social and Personality Psychology Compass, 9(9), 468-480. https://doi.org/10.1111/spc3.12193

Gómez, Á., Bélanger, J., Chinchilla, J., Vázquez, A., Schumpe, B., Nisa, C., \& Chiclana, S. (2021). Admiration for Islamist groups encourages self-sacrifice through identity fusion. Humanities and Social Sciences Communications, 8(1), 1-12. https://doi.org/10.1057/s41599-021-00734-9

Gómez, A., Brooks, M. L., Buhrmester, M. D., Vázquez, A., Jetten, J., \& Swann, W. B. (2011a). On the nature of identity fusion: insights into the construct and a new measure. Journal of Personality and Social Psychology, 100(5), 918-933. https://doi.org/10.1037/a0022642

Gómez, Á., Chinchilla, J., Vázquez, A., López-Rodríguez, L., Paredes, B., \& Martínez, M. (2020). Recent advances, misconceptions, untested assumptions, and future research agenda for identity fusion theory. Social and Personality Psychology Compass, 14(6). https://doi.org/10.1111/spc3.12531

Gómez, Á., López-Rodríguez, L., Sheikh, H., Ginges, J., Wilson, L., Waziri, H., Vázquez, A., Davis, R., \& Atran, S. (2017). The devoted actor's will to fight and the spiritual dimension of human conflict. Nature Human Behaviour, 1(9), 673-679. https://doi.org/10.1038/s41562-017-0193-3

Gómez, Á., Morales, J. F., Hart, S., Vázquez, A., \& Swann, W. B., Jr. (2011b). Rejected and excluded forevermore, but even more devoted: irrevocable ostracism intensifies loyalty to the group among identity-fused persons. Personality and Social Psychology Bulletin, 37(12), 1574-1586. https://doi.org/10.1177/0146167211424580 
Gómez, Á., \& Vázquez, A. (2015). The power of 'feeling one’ with a group: identity fusion and extreme pro-group behaviours / El poder de 'sentirse uno' con un grupo: fusión de la identidad y conductas progrupales extremas. Revista De Psicologia Social, 30(3), 481-511. https://doi.org/10.1080/02134748.2015.1065089

Gómez, Á., Vázquez, A., López-Rodríguez, L., Talaifar, S., Martínez, M., Buhrmester, M. D., \& Swann, W. B. (2019). Why people abandon groups: Degrading relational vs collective ties uniquely impacts identity fusion and identification. Journal of Experimental Social Psychology, 85, 103853. https://doi.org/10.1016/j.jesp.2019.103853

Gómez, A., Atran, S., Chinchilla, J., Vázquez, A., López-Rodríguez, L., Paredes, B., Martínez, M., Blanco, L., Alba, B., Bautista, H., Fernández, S., Pozuelo-Rubio, F., González-Álvarez, J. L., Chiclana, S., Valladares-Narganes, H., Alonso, M., RuízAlvarado, A., López-Novo, J. L., \& Davis, R. (2022a). Willingness to sacrifice among convicted Islamist terrorists versus violent gang members and other criminals. Scientific Reports, 12(1), 2596. https://doi.org/10.1038/s41598-022-06590-0

Gómez, A., Chiclana, S., Chinchilla, J., Blanco, L., Alba, B., Bautista, H. \& Pozuelo-Rubio, F. (2022b) The mirage of the jihad. Disenchantment as the pathway to disengagement of female jihadists. A case study about radicalization in Spanish prisons. International Journal of Social Psychology, 37(3), 586-627. https://doi.org/10.1080/02134748.2022.2096254

Hamid, N., Pretus, C., Atran, S., Crockett, M. J., Ginges, J., Sheikh, H., Tobeña, A., Carmona, S., Gómez, A., \& Davis, R. (2019). Neuroimaging 'will to fight'for sacred values: an empirical case study with supporters of an Al Qaeda associate. Royal Society Open Science, 6(6), 181585. https://doi.org/10.1098/rsos.181585 
Hedges, L. V., Tipton, E., \& Johnson, M. C. (2010). Robust variance estimation in metaregression with dependent effect size estimates. Research synthesis methods, 1(1), 3965. https://doi.org/10.1002/jrsm.5

Heger, A. K., \& Gaertner, L. (2018). Testing the identity synergy principle: Identity fusion promotes self and group sacrifice. Self and Identity, 17(5), 487-499. https://doi.org/10.1080/15298868.2017.1422538

Heger, A., Voorhees, V. A., Porter, B., \& Gaertner, L. (2022) Does Identity Fusion Moderate the Motivational Primacy of the Individual Self? Social Psychological and Personality Science, Online advance article, 19485506221141144. https://doi.org/10.1177/19485506221141144

Henrich, J., Heine, S. J., \& Norenzayan, A. (2010). Beyond WEIRD: Towards a broad-based behavioral science. Behavioral and Brain Sciences, 33(2-3), 111-135. https://doi.org/10.1017/S0140525X10000725

Hogg, M. A. (2014). From Uncertainty to Extremism: Social Categorization and Identity Processes. Current Directions in Psychological Science, 23(5), 338-342. https://doi.org/10.1177/0963721414540168

Hornsey, M. J. (2008). Social identity theory and self-categorization theory: A historical review. Social and Personality Psychology Compass, 2(1), 204-222. https://doi.org/10.1111/j.1751-9004.2007.00066.x

Ioannidis, J.P.A. (2008), Interpretation of tests of heterogeneity and bias in meta-analysis. Journal of Evaluation in Clinical Practice, 14: 951957. https://doi.org/10.1111/j.1365-2753.2008.00986.x

Jasko, K., LaFree, G., Piazza, J., \& Becker, M. H. (2022). A comparison of political violence by left-wing, right-wing, and Islamist extremists in the United States and the world. 
Proceedings of the National Academy of Sciences, 119(30), e2122593119. https://doi.org/doi:10.1073/pnas.2122593119

Jetten, J., \& Mols, F. (2021). Support for populist parties: Economic deprivation, cultural backlash, or status anxiety? In Jan-Willem van Prooijen (Ed.) The Psychology of Political Polarization (pp. 97-111). Routledge.

Jiménez, J., Gómez, Á., Buhrmester, M. D., Vázquez, A., Whitehouse, H., \& Swann, W. B. (2016). The Dynamic Identity Fusion Index. Social Science Computer Review, 34(2), 215-228. https://doi.org/10.1177/0894439314566178

Joo, M., \& Park, S. W. (2017). Effect of identity fusion on decision to make extreme sacrifices in romantic relationships: The moderating role of impulsiveness. British Journal of Social Psychology, 56(4), 819-827. https://doi.org/10.1111/bjso.12218

Kavanagh, C. M., Jong, J., McKay, R., \& Whitehouse, H. (2019). Positive experiences of high arousal martial arts rituals are linked to identity fusion and costly pro-group actions. European Journal of Social Psychology, 49(3), 461-481. https://doi.org/10.1002/ejsp.2514

Klein, J. W., \& Bastian, B. (2022). The Fusion-Secure Base Hypothesis. Personality and Social Psychology Review, 0(0). https://doi.org/10.1177/10888683221100883

Kohl, C., McIntosh, E. J., Unger, S., Haddaway, N. R., Kecke, S., Schiemann, J., \& Wilhelm, R. (2018). Online tools supporting the conduct and reporting of systematic reviews and systematic maps: a case study on CADIMA and review of existing tools. Environmental Evidence, 7(1), 8. https://doi.org/10.1186/s13750-018-0115-5

Kossakowski, R., \& Besta, T. (2018). Football, conservative values, and a feeling of oneness with the group: A study of Polish football fandom. East European Politics and Societies: and Cultures, 32(4), 866-891. https://doi.org/10.1177/0888325418756991 
Kunst, J. R., Boos, B., Kimel, S. Y., Obaidi, M., Shani, M., \& Thomsen, L. (2018). Engaging in extreme activism in support of others' political struggles: The role of politically motivated fusion with outgroups. Plos One, 13(1), e0190639. https://doi.org/10.1371/journal.pone.0190639

Kunst, J. R., Dovidio, J. F., \& Thomsen, L. (2019). Fusion with political leaders predicts willingness to persecute immigrants and political opponents. Nature Human Behavior, 3(11), 1180-1189. https://doi.org/10.1038/s41562-019-0708-1

Kunst, J. R., Fischer, R., Sidanius, J., \& Thomsen, L. (2017). Preferences for group dominance track and mediate the effects of macro-level social inequality and violence across societies. Proceedings of the National Academy of Sciences, 114(21), 54075412. https://doi.org/10.1073/pnas.1616572114

Mael, F., \& Ashforth, B. E. (1992). Alumni and their alma mater: A partial test of the reformulated model of organizational identification. Journal of organizational Behavior, 13(2), 103-123. https://doi.org/10.1002/job.4030130202

Newson, M. (2017). Football, fan violence, and identity fusion. International Review for the Sociology of Sport, 54(4), 431-444. https://doi.org/10.1177/1012690217731293

Newson, M., Bortolini, T., Buhrmester, M., da Silva, S. R., da Aquino, J. N. Q., \& Whitehouse, H. (2018). Brazil's football warriors: Social bonding and inter-group violence. Evolution and Human Behavior, 39(6), 675-683. https://doi.org/10.1016/j.evolhumbehav.2018.06.010

Page, M. J., McKenzie, J. E., Bossuyt, P. M., Boutron, I., Hoffmann, T. C., Mulrow, C. D., Shamseer, L., Tetzlaff, J. M., Akl, E. A., \& Brennan, S. E. (2021). The PRISMA 2020 
statement: an updated guideline for reporting systematic reviews. BMJ, 372 . https://doi.org/10.1136/bmj.n71

Paredes, B., Briñol, P., \& Gómez, Á. (2018). Identity fusion leads to willingness to fight and die for the group: The moderating impact of being informed of the reasons behind other members' sacrifice. Self and Identity, 17(5), 517-530. https://doi.org/10.1080/15298868.2017.1419503

Paredes, B., Santos, D., Briñol, P., Gómez, Á., \& Petty, R. E. (2019). The role of metacognitive certainty on the relationship between identity fusion and endorsement of extreme pro-group behavior. Self and Identity, 19(7), 804-824. https://doi.org/10.1080/15298868.2019.1681498

Peterson, R. A., \& Brown, S. P. (2005). On the use of beta coefficients in meta-analysis. Journal of Applied Psychology, 90(1), 175. https://doi.org/10.1037/0021-9010.90.1.175

Pretus, C., Hamid, N., Sheikh, H., Gómez, Á., Ginges, J., Tobeña, A., Davis, R., Vilarroya, O., \& Atran, S. (2019). Ventromedial and dorsolateral prefrontal interactions underlie will to fight and die for a cause. Social Cognitive and Affective Neuroscience, 14(6), 569-577. https://doi.org/10.1093/scan/nsz034

Pustejovsky, J. E., \& Rodgers, M. A. (2019). Testing for funnel plot asymmetry of standardized mean differences. Research Synthesis Methods, 10(1), 57-71. https://doi.org/10.1002/jrsm.1332

Schubert, T. W., \& Otten, S. (2002). Overlap of self, ingroup, and outgroup: Pictorial measures of self-categorization. Self and Identity, 1(4), 353-376. https://doi.org/10.1080/152988602760328012 
Sheikh, H., Gómez, Á., \& Atran, S. (2016). Empirical Evidence for the Devoted Actor Model. Current Anthropology, 57(S13), S204-S209. https://doi.org/10.1086/686221

Sidanius, J., \& Pratto, F. (2001). Social dominance: An intergroup theory of social hierarchy and oppression. Cambridge University Press. Simon, B., \& Grabow, O. (2010). The politicization of migrants: Further evidence that politicized collective identity is a dual identity. Political Psychology, 31(5), 717-738. https://doi.org/10.1111/j.14679221.2010.00782.x

Stanley, T. D. (2017). Limitations of PET-PEESE and other meta-analysis methods. Social Psychological and Personality Science, 8(5), 581-591. https://doi.org/10.1177\%2F1948550617693062

Swann, W. B., \& Buhrmester, M. D. (2015). Identity Fusion. Current Directions in Psychological Science, 24(1), 52-57. https://doi.org/10.1177/0963721414551363

Swann, W. B., Buhrmester, M. D., Gómez, A., Jetten, J., Bastian, B., Vázquez, A., Ariyanto, A., Besta, T., Christ, O., Cui, L., Finchilescu, G., Gonzalez, R., Goto, N., Hornsey, M., Sharma, S., Susianto, H., \& Zhang, A. (2014a). What makes a group worth dying for? Identity fusion fosters perception of familial ties, promoting self-sacrifice. Journal of Personality and Social Psychology, 106(6), 912-926. https://doi.org/10.1037/a0036089

Swann, W. B., Gómez, Á., Vázquez, A., Guillamón, A., Segovia, S., \& Carillo, B. (2015). Fusion with the Cross-Gender Group Predicts Genital Sex Reassignment Surgery. Archives of Sexual Behavior, 44(5), 1313-1318. https://doi.org/10.1007/s10508-014$0470-4$ 
Swann, W. B., Gómez, A., Buhrmester, M. D., Lopez-Rodriguez, L., Jimenez, J., \& Vázquez, A. (2014b). Contemplating the ultimate sacrifice: identity fusion channels pro-group affect, cognition, and moral decision making. Journal of Personality and Social Psychology, 106(5), 713-727. https://doi.org/10.1037/a0035809

Swann, W. B., Jetten, J., Gómez, A., Whitehouse, H., \& Bastian, B. (2012). When group membership gets personal: a theory of identity fusion. Psychological Review, 119(3), 441-456. https://doi.org/10.1037/a0028589

Swann, W. B., Jr., Gómez, A., Dovidio, J. F., Hart, S., \& Jetten, J. (2010). Dying and killing for one's group: identity fusion moderates responses to intergroup versions of the trolley problem. Psycholocial Science, 21(8), 1176-1183. https://doi.org/10.1177/0956797610376656

Swann, W. B., Jr., Gómez, A., Seyle, D. C., Morales, J. F., \& Huici, C. (2009). Identity fusion: the interplay of personal and social identities in extreme group behavior. Journal of Personality and Social Psychology, 96(5), 995-1011. https://doi.org/10.1037/a0013668

Tajfel, H., Turner, J. C., Austin, W. G., \& Worchel, S. (1979). An integrative theory of intergroup conflict. In M. J. Hatch \& M. Schultz (Eds.), Organizational identity: A reader (pp. 56-65). Oxford University Press.

Talaifar, S., \& Swann, W. B. (2019). Deep alignment with country shrinks the moral gap between Conservatives and Liberals. Political Psychology, 40(3), 657-675. https://doi.org/10.1111/pops.12534

Tanner-Smith, E. E., \& Tipton, E. (2014). Robust variance estimation with dependent effect sizes: practical considerations including a software tutorial in Stata and SPSS. Research Synthesis Methods, 5(1), 13-30. https://doi.org/10.1002/jrsm.1091 
Triandis, H. (1988). Collectivism v. Individualism: A Reconceptualisation of a Basic Concept in Cross-cultural Social Psychology. In G. K. Verma \& C. Bagley (Eds.), CrossCultural Studies of Personality, Attitudes and Cognition (pp. 60-95). Palgrave Macmillan UK. https://doi.org/10.1007/978-1-349-08120-2_3

Turner, J. C., Hogg, M. A., Oakes, P. J., Reicher, S. D., \& Wetherell, M. S. (1987). Rediscovering the social group: a self-categorization theory. Blackwell.

Van Zomeren, M., Spears, R., Fischer, A. H., \& Leach, C. W. (2004). Put your money where your mouth is! Explaining collective action tendencies through group-based anger and group efficacy. Journal of Personality and Social Psychology, 87(5), 649. https://doi.org/10.1037/0022-3514.87.5.649

van Zomeren, M., Postmes, T., \& Spears, R. (2008). Toward an integrative social identity model of collective action: A quantitative research synthesis of three sociopsychological perspectives. Psychological Bulletin, 134(4), 504-535. https://doi.org/10.1037/0033-2909.134.4.504

Vázquez, A., Gómez, Á., Ordoñana, J. R., \& Paredes, B. (2015). From interpersonal to extended fusion: relationships between fusion with siblings and fusion with the country / Desde la fusión interpersonal a la fusión extendida: Relaciones entre la fusión con los hermanos y la fusión con el país. Revista De Psicologia Social, 30(3), $512-530$. https://doi.org/10.1080/02134748.2015.1093755

Vázquez, A., Gómez, Á., Ordoñana, J. R., Swann, W. B., \& Whitehouse, H. (2017). Sharing genes fosters identity fusion and altruism. Self and Identity, 16(6), 684-702. https://doi.org/10.1080/15298868.2017.1296887

Vázquez, A., Ordoñana, J. R., Whitehouse, H., \& Gómez, Á. (2019). Why die for my sibling? The positive association between identity fusion and imagined loss with endorsement 
of self-sacrifice / ¿Por qué morir por un hermano? La asociación positiva entre la fusión de identidad y la pérdida imaginada con la disposición al autosacrificio. Revista De Psicologia Social, 34(3), 413-438. https://doi.org/10.1080/02134748.2019.1639343

Vignoles, V. L. (2018). Identity: Personal AND Social. In K. Deaux \& M. Snyder (Eds.), The Oxford handbook of personality and social psychology (pp. 289-315). Oxford University Press.

White, FA, Newson, M, Verrelli, S, \& Whitehouse, H. Pathways to prejudice and outgroup hostility: Group alignment and intergroup conflict among football fans. Journal of Applied Social Psychology 2021; 51: 660- 666. https://doi.org/10.1111/jasp.12773

Whitehouse, H., Jong, J., Buhrmester, M. D., Gómez, A., Bastian, B., Kavanagh, C. M., Newson, M., Matthews, M., Lanman, J. A., McKay, R., \& Gavrilets, S. (2017). The evolution of extreme cooperation via shared dysphoric experiences. Scientific Reports, 7, 44292. https://doi.org/10.1038/srep44292

Whitehouse, H., McQuinn, B., Buhrmester, M., \& Swann, W. B. (2014). Brothers in arms: Libyan revolutionaries bond like family. Proceedings of the National Academy of Sciences, 111(50), 17783-17785. https://doi.org/10.1073/pnas.1416284111

Whitehouse, H. (2018). Dying for the group: Towards a general theory of extreme selfsacrifice. Behavioral and Brain Sciences, 41, e192. https://doi.org/10.1017/S0140525X18000249

Wilkinson, R. (2005). The impact of inequality. The New Press.

Wolfowicz, M., Litmanovitz, Y., Weisburd, D., \& Hasisi, B. (2021). Cognitive and behavioral radicalization: A systematic review of the putative risk and protective factors. Campbell Systematic Reviews, 17(3), e1174. https://doi.org/10.1002/cl2.1174 